\title{
Fingerprinting the Spatial Sources of Fine-grained Sediment Deposited in the Bed of the Mehran River Draining into the Northern Coast of the Persian Gulf using Elemental Geochemistry
}

\author{
Atefe Fatahi \\ University of Hormozgan \\ Hamid Gholami ( $\nabla$ hgholami@hormozgan.ac.ir) \\ University of Hormozgan \\ Yahya Esmaeilpour \\ University of Hormozgan \\ Aboalhasan Fathabadi \\ Gonbad Kavous University
}

\section{Research Article}

Keywords: Sediment source fingerprinting, statistical tests, generalized likelihood uncertainty estimation, virtual sediment mixtures

Posted Date: October 28th, 2021

DOI: https://doi.org/10.21203/rs.3.rs-1012154/v1

License: (c) (i) This work is licensed under a Creative Commons Attribution 4.0 International License.

Read Full License 
1 Fingerprinting the spatial sources of fine-grained sediment deposited in the bed

2

3

4

5

6

7

\title{
of the Mehran River draining into the northern coast of the Persian Gulf using
}

\section{elemental geochemistry}

\author{
Atefe Fatahi ${ }^{1 a}$ Hamid Gholami ${ }^{1 * a}$ Yahya Esmaeilpour ${ }^{1}$ Aboalhasan Fathabadi ${ }^{2}$ \\ 1. Department of Natural Resources Engineering, University of Hormozgan, Bandar-Abbas, Hormozgan, \\ Iran. \\ 2. Department of Range and Watershed Management, Gonbad Kavous University, Gonbad Kavous, \\ Golestan Province, Iran. \\ * Corresponding authors: Hamid Gholami, Email: hgholami@hormozgan.ac.ir; and Yahya Esmaeilpour, \\ Email:y.esmaeilpour@hormozgan.ac.ir.
}

a: These authors contributed equally to this study.

\section{Abstract}

Accurate information on the sources of suspended sediment in riverine systems is essential to target mitigation. Accordingly, we applied a generalized likelihood uncertainty estimation (GLUE) framework for quantifying contributions from three sub-basin spatial sediment sources in the Mehran River catchment draining into the Persian Gulf, Hormozgan province, southern Iran. A total of 28 sediment samples were collected from the three sub-basin sources and six from the overall outlet. 43 geochemical elements (e.g., major, trace and rare earth elements) were measured in the samples. Four different combinations of statistical tests comprising: 1) traditional range test (TRT), Kruskal-Wallis (KW) H-test and stepwise discriminant function analysis (DFA) (TRT+KW+DFA); 2) traditional range test using mean values (RTM) and two additional tests (RTM+KW+DFA); 3) TRT+KW+PCA (principle component analysis), and; 4) $\mathrm{RTM}+\mathrm{KW}+\mathrm{PCA}$, were used to the spatial sediment source discrimination. Tracer bi-plots were 
24 used as an additional step to assess the tracers selected in the different final composite

25 signatures for source discrimination. The predictions of spatial source contributions generated

26 by GLUE were assessed using statistical tests and virtual sample mixtures. On this basis,

$27 \mathrm{TRT}+\mathrm{KW}+\mathrm{DFA}$ and RTM+KW+DFA yielded the best source discrimination and the tracers in these

28 composite signatures were shown by the biplots to be broadly conservative during transportation

29 from source to sink. Using these final two composite signatures, the estimated mean

30 contributions for the western, central and eastern sub-basins, respectively, ranged between 10-

$3160 \%$ (overall mean contribution 36\%), 0.3-16\% (overall mean contribution 6\%) and 38-77\%

32 (overall mean contribution 58\%). In comparison, the final tracers selected using TRT+KW+PCA

33 generated respective corresponding contributions of $1-42 \%$ (overall mean $20 \%$ ), $0.5-30 \%$ (overall

34 mean 12\%) and 55-84\% (overall mean 68\%) compared with 17-69\% (overall mean 41\%), 0.2-12\%

35 (overall mean 5\%) and $29-76 \%$ (overall mean $54 \%$ ) using the final tracers selected by

36 RTM+KW+PCA. Based on the mean absolute fit (MAF; $\geq 95 \%$ for all target sediment samples) and

37 goodness-of-fit (GOF; $\geq 99 \%$ for all samples), GLUE with the final tracers selected using TRT+KW+PCA performed slightly better than GLUE with the final signatures selected by the three other combinations of statistical tests. Based on the virtual mixture tests, however, predictions

40 provided by GLUE with the final tracers selected using TRT+KW+DFA and RTM+KW+DFA (mean

$41 \mathrm{MAE}=11 \%$ and mean RMSE $=13 \%$ ) performed marginally better than GLUE with RTM+KW+PCA

42 (mean MAE $=14 \%$ and mean RMSE $=16 \%)$ and GLUE with TRT+KW+PCA (mean MAE $=17 \%$ and

43 mean RMSE $=19 \%)$. The estimated source proportions can help watershed engineers plan the 44 targeting of conservation programmes for soil and water resources. 
45 Key words: Sediment source fingerprinting, statistical tests, generalized likelihood uncertainty estimation, virtual sediment mixtures

\section{Introduction}

Accelerated soil erosion by water is an environmental threat on different continents including Asia (e.g. Iran, China, India), North America (e.g., Canada), Europe (especially the Mediterranean regions) and Africa (Koiter et al., 2013; Mararakanye and Sumner, 2017; Mohammadifar et al., 2021; Marzolff et al., 2011). Elevated suspended sediment loads in riverine systems resulting from the accelerated erosion due to human activities are a serious threat to

53 the sustainable management of watersheds and ecosystem services therein worldwide (Collins

54 et al., 2020). Consequently, identifying the sources of suspended sediment in a watershed is essential to target mitigation and to help remedy problems such as eutrophication, and siltation

56 of reservoirs. In particular, well-designed policies and control measures for protecting finite soil

57 and water resources are dependent on reliable and scale-appropriate information on the key sources of the sediment problem which in manifested in the form of both on-site and off-site 59 impacts (Collins et al., 2020).

Today, sediment source fingerprinting (SSF) is increasingly applied to document sediment

61 sources at multiple scales in differing environments. For example, SSF has been applied to 62 quantify the provenance of riverine suspended sediment (Collins et al., 1997; Walling, 2013;

63 Dutton et al., 2013; Collins and Walling, 2002), aeolian sands (Liu et al., 2016; Gholami et al., 64 2017; Nosrati et al., 2021; Ghoalmi et al., 2019b; Niu et al., 2020; Telfer et al., 2020; Zhao et al., 65 2020;2021), atmospheric dust (Nosrati et al., 2020; Gholami et al., 2020; Behrooz et al., 2019) 
and loess deposits (Li et al., 2019; 2020). SSF is founded on measuring the different properties

67 of watershed source material and target sediment samples and their comparison. To date, the different properties used in SSF include colour, mineralogy, geochemical elements (e.g., major, trace and rare earth (REE) elements), isotopic signatures and ratios (e.g., ${ }^{87} \mathrm{Sr} /{ }^{86} \mathrm{Sr}, \delta^{13} \mathrm{C}$ and $\delta^{15} \mathrm{~N}$ ), REE indices, weathering indices, fallout radionuclides (FRNs) and absolute particle size (Habibi et al., 2019; Walling et al., 2005; Collins et al., 1998; LeGall et al., 2016; Laceby et al., 2015a; Pulley 72 and Collins, 2019).

In the last two decades, efforts exploring the uncertainties associated with both aeolian and fluvial SSF results has attracted increasing attention (Walling, 2013; Collins et al., 2017, 2020). The frameworks used to quantify uncertainty associated with SSF estimates can be divided into 76 three groups comprising Monte Carlo simulation - the most commonly applied framework 77 (Collins et al., 2012; Pulley et al., 2020; Koiter et al., 2013), Bayesian approaches (Massoudieh et al., 2013; Cooper et al., 2014; Li et al., 2020; Gholami et al., 2017) and generalized likelihood 79 uncertainty estimation (GLUE; Rowan et al., 2000). Among these three frameworks, the GLUE model has been used far less frequently and, in many cases, has been applied in conjunction with 81 quantifying the provenance of aeolian, rather than fluvial, sediments (Behrooz et al., 2019; Telfer 82 et al., 2020; Gholami et al., 2020; Li et al., 2020). To the best of our knowledge, GLUE has not 83 been used to quantify uncertainty associated with estimating the spatial sources of fluvial suspended sediment in river catchments. Despite this less frequent application of GLUE, it is useful to bear in mind that Bayesian modelling, as an alternative to GLUE, is more sophisticated 86 but equally more demanding, since it uses different distributions and transformations (e.g., 87 posterior and prior, Dirichlet), centered log ratio (CLR; Semmens et al., 2009), additive log-ratio 
88 (ALR; Brewer et al., 2005) and iso-metric log ratio (ILR;Egozcue et al., 2003)) in the data structure.

89 Regardless of the approach used to estimate uncertainties associated with predicted sediment

90 source proportions, the uncertainties associated with the SSF approach may originate from a

91 variety of sources, including within-source group tracer variability, tracer selection, limited

92 numbers of source material or target sediment samples, laboratory analyses, and source group

93 classification (Pulley et al., 2015; Pulley and Collins, 2019; Collins et al., 2020).

Given the above background, the primary goal of this study was to apply geochemical SSF

95 within GLUE framework in the estimation of sub-basin spatial sediment source contributions in

96 the arid Mehran River catchment in southern Iran, which drains into the Persian Gulf. The

97 accuracy of GLUE predictions generated using four different sets of statistical tests for

98 discriminating three sub-basin spatial sources was evaluated using 10 virtual sediment (VS)

99 samples with known source contributions using the root mean square error (RMSE) and mean

100 absolute error (MAE).

101 2. Materials and methods

$102 \quad 2.1$ Study area

The Mehran River catchment $\left(2142 \mathrm{~km}^{2}\right)$ is located in the western part of Hormozgan

104 province, southern Iran $\left(26^{\circ} 42^{\prime}\right.$ to $27^{\circ} 16^{\prime} \mathrm{N}$, and $54^{\circ} 30^{\prime}$ to $55^{\circ} 26^{\prime}$ ") (Fig.1). The study area is

105 surrounded by Bandar-e-Khamir and Bandar-e-Langeh on the eastern and western sides,

106 respectively. It can be divided into three sub-basins comprising a western sub-basin $\left(1611 \mathrm{~km}^{2}\right)$,

107 a central sub-basin $\left(106 \mathrm{~km}^{2}\right)$ and an eastern sub-basin $\left(425 \mathrm{~km}^{2}\right)$. The river is $86 \mathrm{~km}$ long.

108 Elevation ranges between $-44 \mathrm{~m}$ in the eastern part of the study area in the vicinity of the 
existing mangrove forests in the vicinity of the outlet located on the northern coast of the Persian

111 Gulf, the study catchment is earmarked as being important environmentally. Geologically, the

112 study area is underlain by diverse geological units including Asmari-Jahrom, Jahrom, Tuffaceous

113 shale, Bangestan group, Gachsaran, Mishan, Aghajari, Razak, Bakhtyari, Quaternary fan terraces

114 and the Hormoz series with high salt content. The main channel of the Mehran River is 115 established on Quaternary fans and terraces.

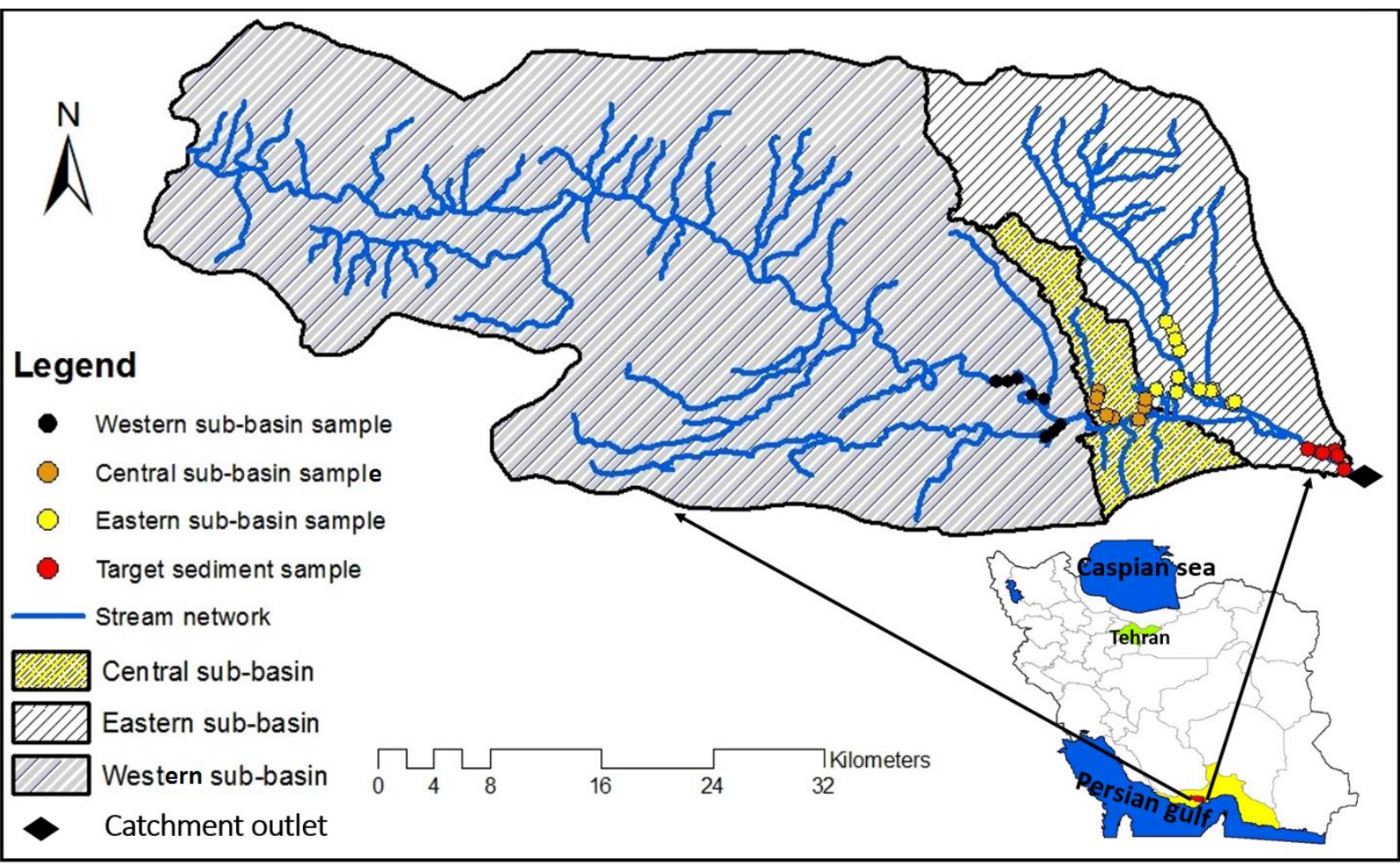

117 Figure 1: Location of the sub-basin and catchment outlet sediment sampling sites in the study area in 118 Hormozgan province, Iran. The red and yellow shading in the bottom map indicate the study catchment 119 and Hormozgan province, respectively.

120

\subsection{Sampling, sample preparation and laboratory analysis}


123 River catchment were classified as the western, central and eastern sub-basins. A total of 28 124 surficial samples were collected from the fine-grained materials deposited in the bed of the main 125 channel of the sub-basin spatial sources, comprising eight for the western, eight for the central 126 and 12 for the eastern sub-basin, respectively (Fig. 2a,b,c). A total of six target sediment samples 127 were collected from the fine-grained sediments deposited in the bed of the Mehran River main 128 stem in the vicinity of the overall outlet (Fig. 2d). Samples were air dried and sieved to separate 129 the $<63 \mu \mathrm{m}$ fraction. The results of the granulometry analysis for the source and target sediment 130 samples are presented in Table 1 . The conventional $<63 \mu \mathrm{m}$ fraction was selected as this is the 131 most geochemically active (Horowitz, 1991). Aqua regia was used to digest the sieved samples 132 and then the solutions were analysed for tracer pseudo-content using inductively coupled plasma 133 atomic emission spectroscopy (ICP-OES) in the Central Laboratory of the University of 134 Hormozgan. In total, 43 geochemical elements (Al, As, Ba, Be, Bi, Cu Ce, Co, Cr, Cs, Er, Fe, K, Li, $135 \mathrm{Mo}, \mathrm{Ga}, \mathrm{Gd}, \mathrm{Hf}, \mathrm{Ho}, \mathrm{In}, \mathrm{Mg}, \mathrm{Mn}, \mathrm{Na}, \mathrm{Nb}, \mathrm{Ni}, \mathrm{Te}, \mathrm{Zn}, \mathrm{P}, \mathrm{Pb}, \mathrm{S}, \mathrm{Sc}, \mathrm{Sm}, \mathrm{Sn}, \mathrm{Ta}, \mathrm{Tb}, \mathrm{V}, \mathrm{W}, \mathrm{Ag}, \mathrm{Zr}, \mathrm{Ca}, \mathrm{Eu}$ 136 and La) were measured in the 34 source material and target sediment samples. 
147 Table 1: The results of granulometry analysis for source and target sediment samples using dry sieving.

\begin{tabular}{|c|c|c|c|c|c|c|c|c|c|}
\hline \multirow{2}{*}{\multicolumn{2}{|c|}{$\begin{array}{l}\text { Sample } \\
\text { no }\end{array}$}} & \multicolumn{8}{|c|}{ Particle size class (\% by mass) } \\
\hline & & $\begin{array}{l}>4.75 \\
\mathrm{~mm} \\
\text { Fine gravel }\end{array}$ & $\begin{array}{l}4.75 \\
\mathrm{~mm} \\
\text { Very fine } \\
\text { gravel }\end{array}$ & $\begin{array}{l}3.35 \\
\mathrm{~mm} \\
\text { Very } \\
\text { coarse } \\
\text { sand }\end{array}$ & $\begin{array}{l}0.85 \mathrm{~mm} \\
\text { Coarse } \\
\text { sand }\end{array}$ & $\begin{array}{l}0.355 \\
\mathrm{~mm} \\
\text { Medium } \\
\text { sand }\end{array}$ & $\begin{array}{l}0.180 \mathrm{~mm} \\
\text { Fine sand }\end{array}$ & $\begin{array}{l}0.125 \\
\mathrm{~mm} \\
\text { Very fine } \\
\text { sand }\end{array}$ & $\begin{array}{l}0.063 \\
\mathrm{~mm} \\
\text { Silt and } \\
\text { clay }\end{array}$ \\
\hline \multirow{8}{*}{ 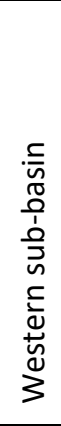 } & SS1 & 4.78 & 12.97 & 11.17 & 36.76 & 17.73 & 6.56 & 5.37 & 4.65 \\
\hline & SS2 & 4.71 & 4.27 & 3.52 & 28.51 & 29.74 & 16.22 & 9.04 & 3.98 \\
\hline & SS3 & 17.16 & 13.91 & 4.26 & 19.31 & 32.36 & 5.08 & 4.07 & 3.85 \\
\hline & SS4 & 52.45 & 16.42 & 2.19 & 3.48 & 11.94 & 6.72 & 4.7 & 2.1 \\
\hline & SS5 & 32.88 & 29.09 & 4.08 & 10.04 & 15.35 & 3.92 & 2.05 & 2.6 \\
\hline & SS6 & 50.01 & 26.69 & 2.67 & 3.19 & 4.68 & 4.01 & 2.57 & 6.18 \\
\hline & SS7 & 5.08 & 8.6 & 8.04 & 57.45 & 8.27 & 5.33 & 3.01 & 4.21 \\
\hline & SS8 & 31.78 & 40.54 & 6.25 & 10.2 & 5.23 & 2.79 & 1.44 & 1.76 \\
\hline \multirow{8}{*}{ 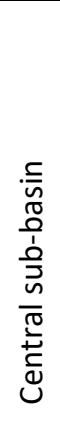 } & SS1 & 11.41 & 31.94 & 12.07 & 31.3 & 7.53 & 2.32 & 1.59 & 1.85 \\
\hline & SS2 & 4.82 & 18.31 & 7.54 & 25.67 & 31.79 & 5.99 & 2.75 & 3.12 \\
\hline & SS3 & 27.07 & 16.66 & 3.66 & 8.51 & 12.68 & 14.57 & 4.58 & 12.27 \\
\hline & SS4 & 14.53 & 21.04 & 10.24 & 37.46 & 10.57 & 2.42 & 1.66 & 2.09 \\
\hline & SS5 & 24.37 & 14.31 & 7.9 & 10.32 & 7.03 & 7.9 & 16.86 & 11.3 \\
\hline & SS6 & 11.41 & 28.87 & 7.3 & 11.48 & 17.79 & 9.91 & 11.33 & 1.9 \\
\hline & SS7 & 12.11 & 47.03 & 16.09 & 13.12 & 2.85 & 3.03 & 3 & 2.77 \\
\hline & SS8 & 35.38 & 34.51 & 6.77 & 11.86 & 3.44 & 1.95 & 1.97 & 4.12 \\
\hline \multirow{8}{*}{ 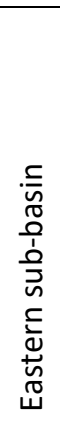 } & SS1 & 11.25 & 30.8 & 14.72 & 34.39 & 2.94 & 1.77 & 1.84 & 2.3 \\
\hline & SS2 & 7.79 & 20.44 & 13.1 & 42.51 & 8.83 & 2.6 & 1.75 & 2.97 \\
\hline & SS3 & 28.74 & 45.38 & 7.9 & 10.08 & 2.83 & 1.86 & 1.51 & 1.7 \\
\hline & SS4 & 20.35 & 30.35 & 11.42 & 24.14 & 6.43 & 2.59 & 2.33 & 2.39 \\
\hline & SS5 & 23.81 & 47.19 & 7.76 & 11.65 & 3.69 & 1.79 & 2.03 & 2.09 \\
\hline & SS6 & 13.02 & 41.28 & 9.81 & 20.11 & 8.36 & 2.73 & 2.23 & 2.47 \\
\hline & SS7 & 21.41 & 44.34 & 7.13 & 10.36 & 7.31 & 2.91 & 4.14 & 2.4 \\
\hline & SS8 & 20.17 & 39.66 & 8.98 & 18.99 & 5.98 & 2.11 & 2.02 & 2.1 \\
\hline
\end{tabular}




\begin{tabular}{|c|c|c|c|c|c|c|c|c|c|}
\hline & SS9 & 9.91 & 17.81 & 6.18 & 31.98 & 27.03 & 3.66 & 2.67 & 0.76 \\
\hline & SS10 & 3.58 & 34.1 & 14.34 & 35.7 & 7.75 & 1.53 & 1.47 & 1.52 \\
\hline & SS11 & 3.2 & 16.97 & 19.36 & 48.83 & 6.58 & 1.95 & 1.43 & 1.67 \\
\hline & SS12 & 5.64 & 16.29 & 10.5 & 46.95 & 13.86 & 2.46 & 2.46 & 1.85 \\
\hline \multirow{6}{*}{ 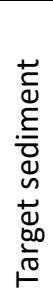 } & S1 & 7.97 & 11.68 & 5 & 55.93 & 13.52 & 2.36 & 1.91 & 1.64 \\
\hline & S2 & 0 & 2.3 & 2.31 & 33.12 & 50.19 & 4.77 & 3.78 & 3.54 \\
\hline & S3 & 15.73 & 16.21 & 5.88 & 10.71 & 22.47 & 12.66 & 9.21 & 7.13 \\
\hline & S4 & 9.14 & 11.79 & 4.2 & 23.26 & 37.15 & 7.14 & 3.17 & 4.16 \\
\hline & S5 & 2.42 & 6.28 & 2.79 & 39.58 & 36.41 & 3.76 & 2.8 & 5.96 \\
\hline & S6 & 4.5 & 10.7 & 3.98 & 41.84 & 28.97 & 5.59 & 2.53 & 1.89 \\
\hline
\end{tabular}

148

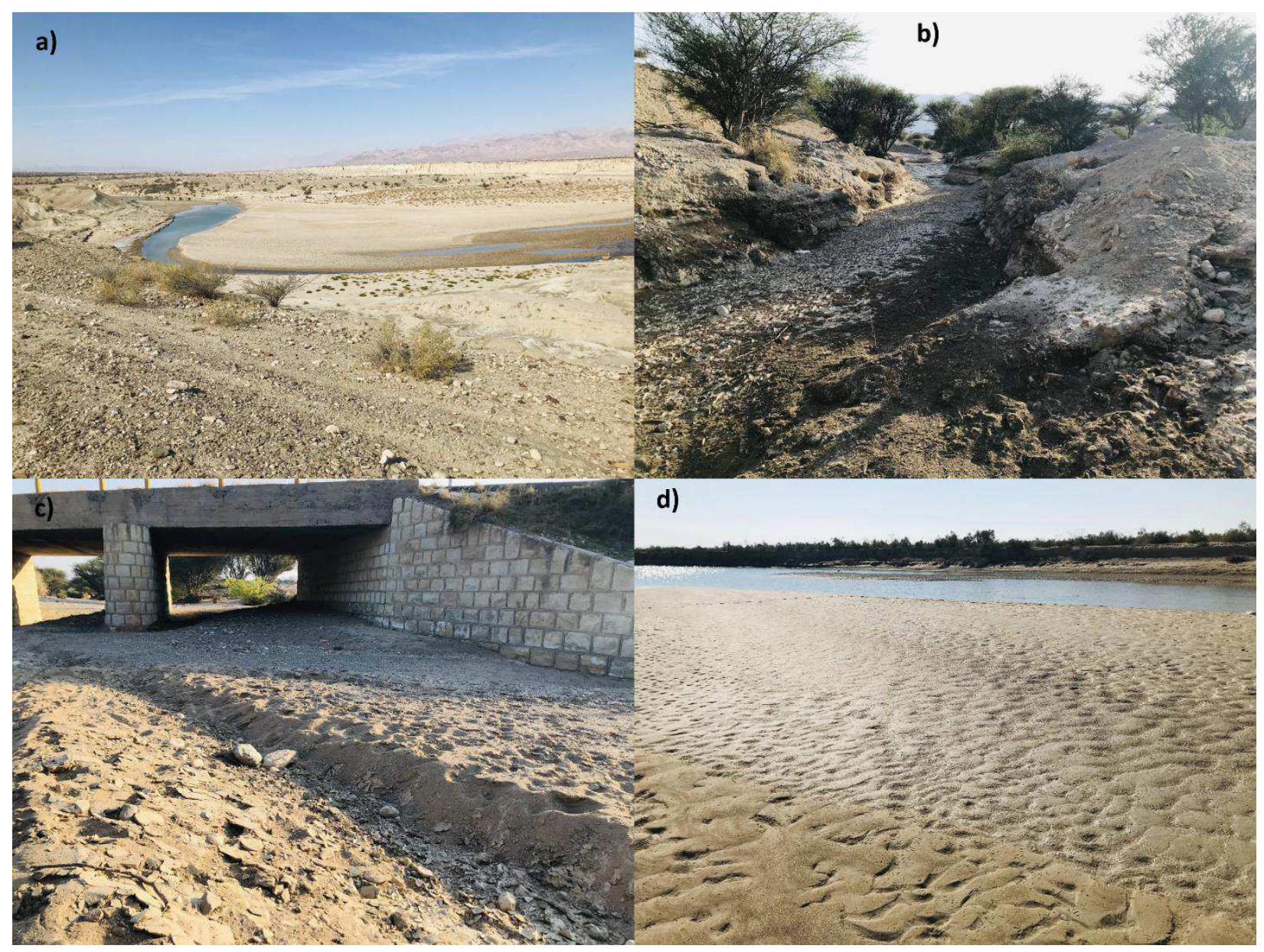

150 Figure 2: Photographs showing the sediment deposits where the samples were collected from: a) western

151 sub-basin; b) central sub-basin; c) eastern sub-basin, and; d) the main channel of the Mehran River in the

152 vicinity of the overall catchment outlet. 
A wide range of methods including individual statistical tests such as the Kruskal-Wallis $\mathrm{H}$

156 test, stepwise discriminant function analysis, principle component analysis, or combined 157 statistical procedures, are used to discriminate the potential sources of target sediment samples 158 (Collins et al., 2017). Here, we used four combinations of statistical procedures. The first comprised a TRT (based on the minimum and maximum ranges of tracer concentrations in the source and target sediment samples) for tracer conservation plus the (KW test for individual

161 tracer discriminatory power and DFA for composite signature discriminatory power. The second 162 comprised a RTM (range test using mean tracer values in source and target sediment samples) in 163 combination with KW and DFA. The third combination of tests comprised TRT, KW and PCA. The 164 fourth combination combined RTM, KW and PCA. Tracer bi-plots was used for further assessment 165 of source discrimination provided by each final composite signature and of tracer conservation.

\subsection{Generalised Likelihood Uncertainty Estimation (GULE)}

GLUE was first applied to uncertainty modelling and sensitivity analysis for hydrological models by Beven and Binley (1992). In more recent years (2019 to present) GLUE modelling has

169 been applied to quantify uncertainty associated with source contributions to sampled loess 170 deposits, and aeolian dust and sands in Central Asia, Iran and Australia (Li et al., 2020;, Behrooz

171 et al., 2019; Gholami et al., 2020; Telfer et al., 2020). Based on GLUE, we can quantify the 172 uncertainties associated with SSF results via the following five key steps: 
173 Step 1: application of LHS (Latin Hypercube Sampling) for the random sampling of tracer 174 parameter sets $(10,000$ iterations $)$. At this stage, two boundary constraints $\left(0 \leq x_{j} \leq 1\right.$; and $\sum x_{j}=$ 175 1) must be satisfied (Collins et al., 2012);

176 Step 2: use of the Nash-Sutcliffe coefficient (NSC) as the likelihood function (Behrooz et al., 177 2019):

$178 \quad N S C=1-\frac{\sum_{i=1}^{n}\left(a_{o}-a_{S}\right)^{2}}{\sum_{i=1}^{n}\left(a_{o}-a m_{o}\right)^{2}}$

179 where $a_{s}$ and $a_{o}$ indicate the simulated ith final tracer concentration and the measured ith final 180 tracer concentration, respectively. amo represents the mean value of the ith measured tracer 181 concentration in the target sediment sample;

182 Step 3: application of an un-mixing model as follows:

$183 A_{t s}=B_{s} \times C$ (eq. 2)

184 where $C$ is an $\mathrm{m}$ dimensional column vector of the spatial source contributions, $A_{t s}$ indicates an $185 \mathrm{n}$-dimensional column vector of tracer concentrations in the target sediment sample, and $B_{S}$ 186 represents an $\mathrm{n} \times \mathrm{m}$ dimensional matrix representing the mean tracer concentrations in the spatial 187 sub-basin sources;

188 Step 4: division of the tracer parameter sets into behavioural and non-behavioural types (Zhou 189 et al, 2016), and;

190 Step 5: re-scaling of the likelihood weights for the behavioural parameter sets.

191 More details for GLUE modelling can be found in Telfer et al. (2020) and Behrooz et al. (2019).

$192 \quad 2.5$ Assessment of GLUE performance 
194 al., 2003; Laceby and Olley, 2014; Collins et al., 2010; Gholami et al., 2020) were applied to assess 195 the performance of GLUE in estimating the measured tracer concentrations in the target 196 sediment samples collected from the outlet of the Mehran River catchment, viz.:

$197 \quad M A F=1-\frac{1}{n} \times\left(\sum_{i=1}^{n}\left|\frac{b_{i}-\sum_{j=1}^{n} x_{j} a_{j . i}}{b_{i}}\right|\right)$

198

$199 G O F=1-\frac{1}{n} \times \sum_{i=1}^{n}\left\{\left(\frac{\left|b_{i}-\sum_{i=1}^{m} x_{j} a_{j, i}\right|}{b_{i}}\right)^{2}\right\}$

200

201 where $n$ and $m$ are the number of tracers in the final composite signature and number of sub-

202 basin spatial sources $(\mathrm{m}=3)$, respectively. $b_{i}$ is the concentration of the final tracer (i) measured 203 in the target sediment sample, $x_{j}$ indicates the relative contribution of source (j) to the target 204 sediment sample, and $a_{j, i}$ represents the mean concentration of the final tracer (i) in the sub205 basin spatial source (j).

The accuracy of the GLUE predictions of spatial source contributions was assessed using 20710 VS mixtures (Pulley et al., 2020; Gholami et al., 2020; Li et al., 2020). Here, the root mean 208 square error (RMSE) and mean absolute error (MAE) were used to compare the GLUE predictions 209 with known source contributions from the three sub-basin spatial sources, viz.:

210

$$
R M S E=\sqrt{\frac{\sum_{i=1}^{n}\left(X_{K}-X_{P}\right)^{2}}{n}}
$$


$212 \quad M A E=\frac{\sum_{i=1}^{n}\left|X_{K}-X_{P}\right|}{n}$

213

214 where, $X_{K}$ and $X_{P}$ indicate the known contribution from the sub-basin spatial sources in the VS

215 and the corresponding contribution predicted by the GLUE model, respectively. $\mathrm{n}$ is the number

$216(n=3)$ of sub-basin spatial sources.

217 A methodological flowchart is presented in Figure 3.

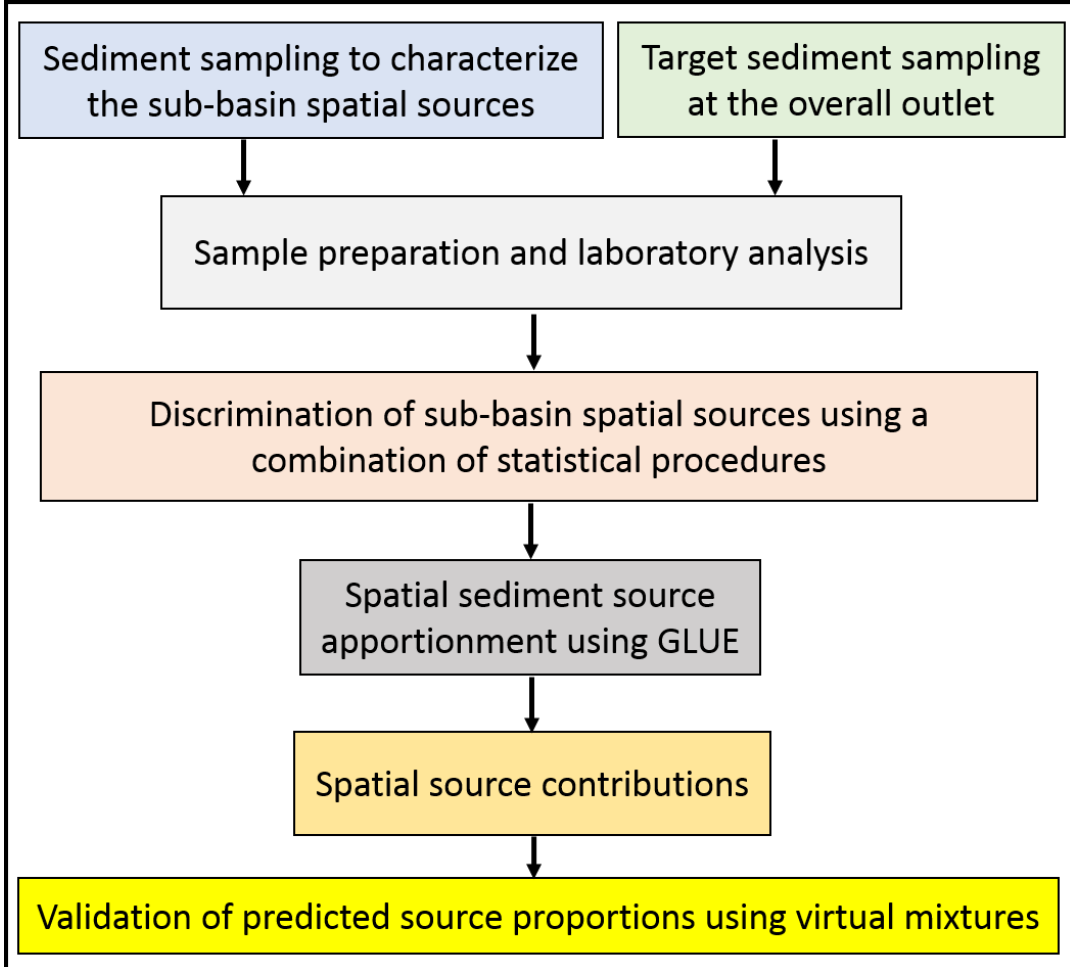

219 Figure 3: Flowchart for the GLUE methodology applied for source fingerprinting of the target sediment 220 samples collected from the Mehran River.

221

222 3. Results and discussion 
225 signature for source apportionment is one of the key stages in successful SSF (Walling et al., 1993;

226 Collins et al., 2017; Gellis and Walling, 2011). Based on TRT, 11 geochemical tracers (Be, Bi, Cs,

$227 \mathrm{Er}, \mathrm{Fe}, \mathrm{K}, \mathrm{Li}, \mathrm{Mo}, \mathrm{Te}, \mathrm{Zn}$ and $\mathrm{Cu}$ ) were identified as non-conservative, meaning that 33 geochemical 228 elements ( $\mathrm{Al}, \mathrm{As}, \mathrm{Ba}, \mathrm{Ce}, \mathrm{Co}, \mathrm{Cr}, \mathrm{Ga}, \mathrm{Gd}, \mathrm{Hf}, \mathrm{Ho}, \mathrm{Mg}, \mathrm{Mn}, \mathrm{Na}, \mathrm{Nb}, \mathrm{Ni}, \mathrm{P}, \mathrm{Pb}, \mathrm{Pr}, \mathrm{Rb}, \mathrm{S}, \mathrm{Sc}, \mathrm{Sm}, \mathrm{Sn}$, $229 \mathrm{Ta}, \mathrm{Tb}, \mathrm{V}, \mathrm{W}, \mathrm{Ag}, \mathrm{Zr}, \mathrm{Ca}$, Eu and La) were conservative. By comparison, using RTM, 18 geochemical 230 tracers (Al, As, Ba, Be, $\mathrm{Co}, \mathrm{Cr}, \mathrm{Fe}, \mathrm{Ga}, \mathrm{K}, \mathrm{Mo}, \mathrm{Na}, \mathrm{Pb}, \mathrm{Sm}, \mathrm{Sn}, \mathrm{Ta}, \mathrm{Tb}, \mathrm{Te}$ and $\mathrm{Zn}$ ) failed the test. 231 Logically, the results for TRT and TRM make sense since TRM is a stricter test meaning that more 232 tracers typically fail this mathematical test for conservative behaviour. Due to immobility and low 233 solubility, rare earth elements (REEs) (e.g., Ce, Gd, Ho, Sc, Sm, Tb, Eu and La) may be useful tracers 234 for identifying the provenance of sediments and the formation mechanism of rocks (Taylor and 235 McLennan, 1985; Habibi et al., 2019).Tracers failing either range test were excluded from further 236 statistical analysis.

\section{$237 \quad 3.2$ Spatial sediment source discrimination}

$238 \quad$ 3.2.1 Stepwise DFA

The results of KW suggested that, among the 32 geochemical tracers passing the TRT, 12

240 (Al, Ce, Hf, Mn, Nb, P, Rb, Sc, Zr, Ca, Eu and La) were significant ( $p \leq 0.05$ ), whist 20 geochemical 241 elements ( $\mathrm{As}, \mathrm{Ba}, \mathrm{Co}, \mathrm{Cr}, \mathrm{Ga}, \mathrm{Gd}, \mathrm{Ho}, \mathrm{Mg}, \mathrm{Na}, \mathrm{Ni}, \mathrm{Pb}, \mathrm{Pr}, \mathrm{S}, \mathrm{Sm}, \mathrm{Sn}, \mathrm{Ta}, \mathrm{Tb}, \mathrm{V}, \mathrm{W}$ and $\mathrm{Ag}$ ) were not 242 statistically significant $(p \geq 0.05)$. The 12 statistically significant tracers were used in stepwise DFA 243 for identifying the final composite signature for discriminating the sub-basin spatial sources of 244 the target sediment samples. Based on the stepwise DFA (Table 2), three geochemical tracers (Zr, 
$245 \mathrm{Mn}$ and P) were selected. The final tracers were selected based on minimizing the Wilks' Lambda

246 values. The values of Wilks' Lambda ranged between 13.9 (for the first step with Zr as the first

247 tracer entered into the model) and 11.3 (for the third step with $\mathrm{P}$ as the third tracer entered into

248 the model).

Among the 25 geochemical tracers (Bi, Ce, Cs, Er, Gd, Hf, Ho, Li, Mg, Mn, Nb, Ni, P, Pr, Rb,

$250 \mathrm{~S}, \mathrm{Sc}, \mathrm{V}, \mathrm{W}, \mathrm{Ag}, \mathrm{Zr}, \mathrm{Ca}, \mathrm{Cu}, \mathrm{Eu}$ and La) passing RTM, 12 geochemical proprieties (Bi, Cs, Er, Gd, Ho,

$251 \mathrm{Mg}, \mathrm{Ni}, \mathrm{Pr}, \mathrm{S}, \mathrm{V}, \mathrm{W}$, and $\mathrm{Ag}$ ) were not statistically significant (with $\mathrm{p} \geq 0.05$ ) according to $\mathrm{KW}$,

252 whereas 13 (Ce, Hf, Li, Mn, Nb, P, Rb, Sc, Zr, Ca, Cu, Eu and La) were significant ( $p \leq 0.05$ ). Overall,

253 the results of stepwise DFA for tracers passing RTM+KW were the same as those identified using

254 TRT+KW+DFA (Table 2, Fig. 4).

255 Table 2: The final composite signature selected by both TRT+KW+DFA and TRM+KW+DFA for 256 discriminating the three sub-basin spatial sources of the six target sediment samples collected at the 257 outlet of the study area.

\begin{tabular}{llll}
\hline Step & Final tracers & Wilks' Lambda & \\
\cline { 3 - 4 } & & Statistic & Sig. \\
\hline 1 & $\mathrm{Zr}$ & 13.9 & 0.000 \\
2 & $\mathrm{Mn}$ & 11.7 & 0.000 \\
3 & $\mathrm{P}$ & 11.3 & 0.000 \\
\hline
\end{tabular}




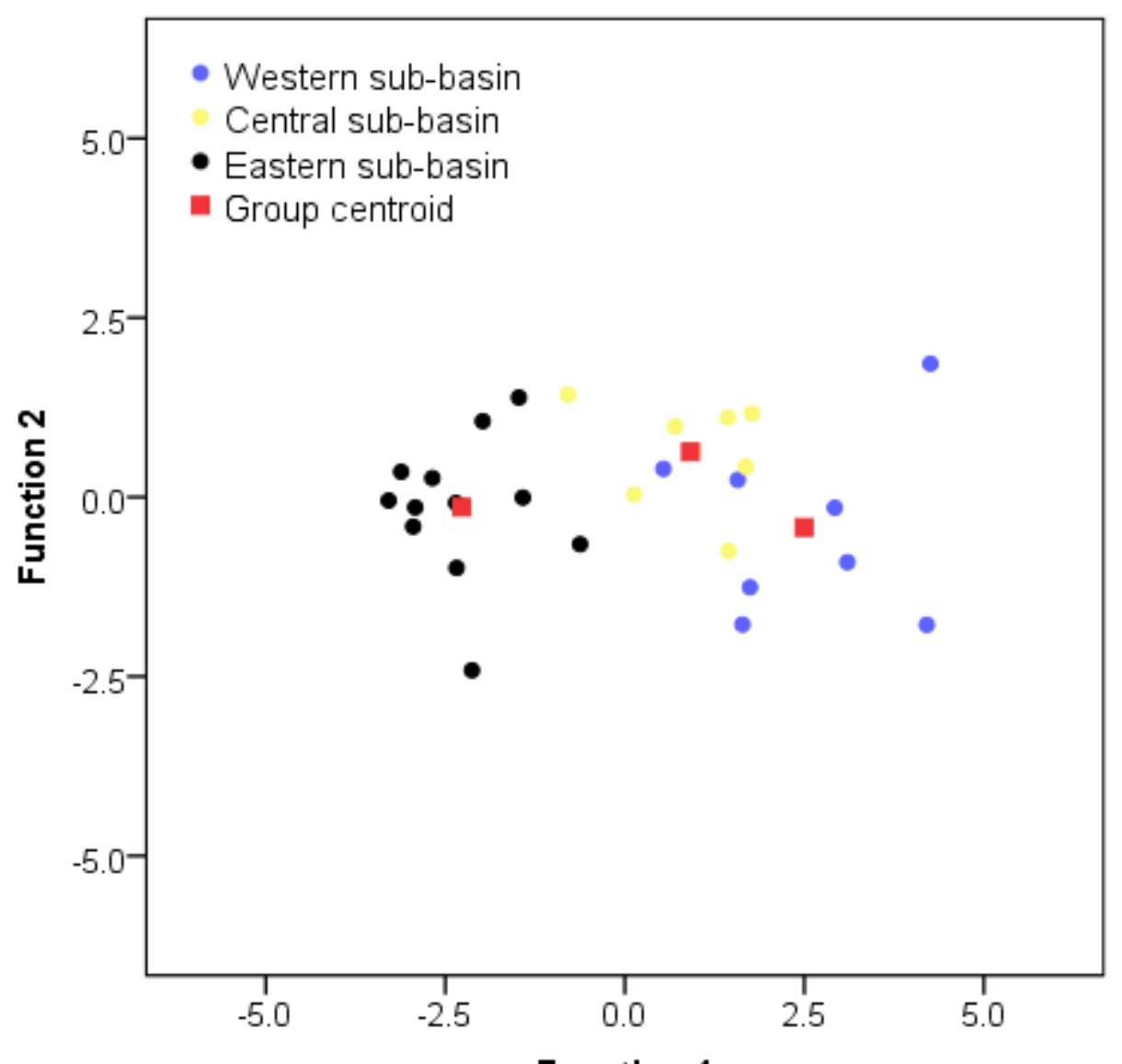

Function 1

260 Figure 4: Two-dimensional scatterplot constructed based on the first and second functions of the stepwise 261 DFA for the tracers selected using either TRT+KW+DFA or TRM+KW+DFA.

263 results, a combination of $\mathrm{Zr}, \mathrm{Mn}$ and $\mathrm{P}$ were able to correctly classify $89.3 \%$ of the sub-basin

264 spatial source sediment samples (Fig. 4).

265 Table 3: Classification results for the three sub-basin spatial sediment sources using stepwise DFA.

\begin{tabular}{|c|c|c|c|c|c|}
\hline \multirow{2}{*}{\multicolumn{2}{|c|}{ No }} & \multicolumn{3}{|c|}{ Predicted group membership } & \multirow[t]{2}{*}{ Total } \\
\hline & & Western sub-basin & Central sub-basin & Eastern sub-basin & \\
\hline \multirow[t]{3}{*}{ Count } & Western sub-basin & 6 & 2 & 0 & 8 \\
\hline & Central sub-basin & 1 & 7 & 0 & 8 \\
\hline & Eastern sub-basin & 0 & 0 & 12 & 12 \\
\hline \multirow[t]{3}{*}{ Percent } & Western sub-basin & 75 & 25 & 0 & 100 \\
\hline & Central sub-basin & 12.5 & 87.5 & 0 & 100 \\
\hline & Eastern sub-basin & 0 & 0 & 100 & 100 \\
\hline
\end{tabular}




\subsubsection{Principle component analysis (PCA)}

12 (Al, Ce, Hf, Mn, Nb, P, Rb, Sc, Zr, Ca, Eu and La) and 13 (Ce, Hf, Li, Mn, Nb, P, Rb, Sc, Zr,

$270 \mathrm{Ca}, \mathrm{Cu}, \mathrm{Eu}$ and $\mathrm{La}$ ) geochemical tracers passing TRT+KW and RTM+KW (Table 4), respectively,

271 were entered into the PCA. Based on Table 4 and Figure 5, the first three PC yielded the most

272 interpretable factor pattern. The initial eigenvalues for components 1 to 3 ranged between 5.6

273 to 1.26 (Fig. 5a). The percentage of the variance explained by these components was calculated

274 as $30.7 \%, 25.9 \%$ and $25.6 \%$, respectively. Based on Figure 5c, the variance of PC1, PC2and PC3

275 was $29.3 \%, 26.6 \%$ and $23.9 \%$, respectively, whereas the initial eigenvalue for these components

276 was estimated to be 5.63, 3.46 and 1.28, respectively. Based on Figures 5b and 5d, projection of

277 the sample cases on the PC plane using PCA indicates that the final set of tracers, selected using

278 a combination of either TRT+KW+PCA or TRM+KW+PCA, provided relatively good discrimination

279 between the three sub-basin spatial sediment sources.

280 Table 4: Results of PCA based on tracers passing TRT+KW and RTM+KW.

\begin{tabular}{llll}
\hline & \multicolumn{3}{c}{ TRT+KW+PCA } \\
\hline Tracer & PC1 & PC2 & PC3 \\
\hline $\mathrm{Al}$ & 0.058 & -0.017 & 0.97 \\
$\mathrm{Ce}$ & 0.94 & 0.26 & 0.029 \\
$\mathrm{Hf}$ & 0.23 & 0.75 & 0.008 \\
$\mathrm{Mn}$ & 0.059 & 0.11 & 0.84 \\
$\mathrm{Nb}$ & 0.29 & 0.71 & 0.30 \\
$\mathrm{P}$ & 0.74 & 0.46 & 0.05 \\
$\mathrm{Rb}$ & -0.165 & -0.515 & 0.73 \\
$\mathrm{Sc}$ & 0.118 & 0.376 & 0.86 \\
$\mathrm{Zr}$ & 0.26 & 0.86 & 0.125 \\
$\mathrm{Ca}$ & 0.48 & 0.69 & -0.189 \\
Eu & 0.91 & 0.28 & 0.12 \\
La & 0.954 & 0.208 & 0.014 \\
\hline \multicolumn{2}{c}{} & RTM+KW+PCA & \\
\hline Tracer & PC1 & PC3
\end{tabular}




\begin{tabular}{llll}
\hline $\mathrm{Ce}$ & 0.94 & -0.003 & 0.26 \\
$\mathrm{Hf}$ & 0.23 & -0.04 & 0.76 \\
$\mathrm{Li}$ & -0.275 & 0.883 & -0.07 \\
$\mathrm{Mn}$ & 0.108 & 0.87 & 0.151 \\
$\mathrm{Nb}$ & 0.275 & 0.194 & 0.758 \\
$\mathrm{P}$ & 0.73 & -0.025 & 0.467 \\
$\mathrm{Rb}$ & -0.214 & 0.721 & -0.402 \\
$\mathrm{Sc}$ & 0.131 & 0.816 & 0.447 \\
$\mathrm{Zr}$ & 0.257 & 0.025 & 0.88 \\
$\mathrm{Ca}$ & 0.531 & -0.221 & 0.63 \\
$\mathrm{Cu}$ & 0.155 & 0.795 & -0.049 \\
$\mathrm{Eu}$ & 0.925 & 0.096 & 0.27 \\
$\mathrm{La}$ & 0.94 & -0.013 & 0.21 \\
\hline
\end{tabular}

281

282

283

284
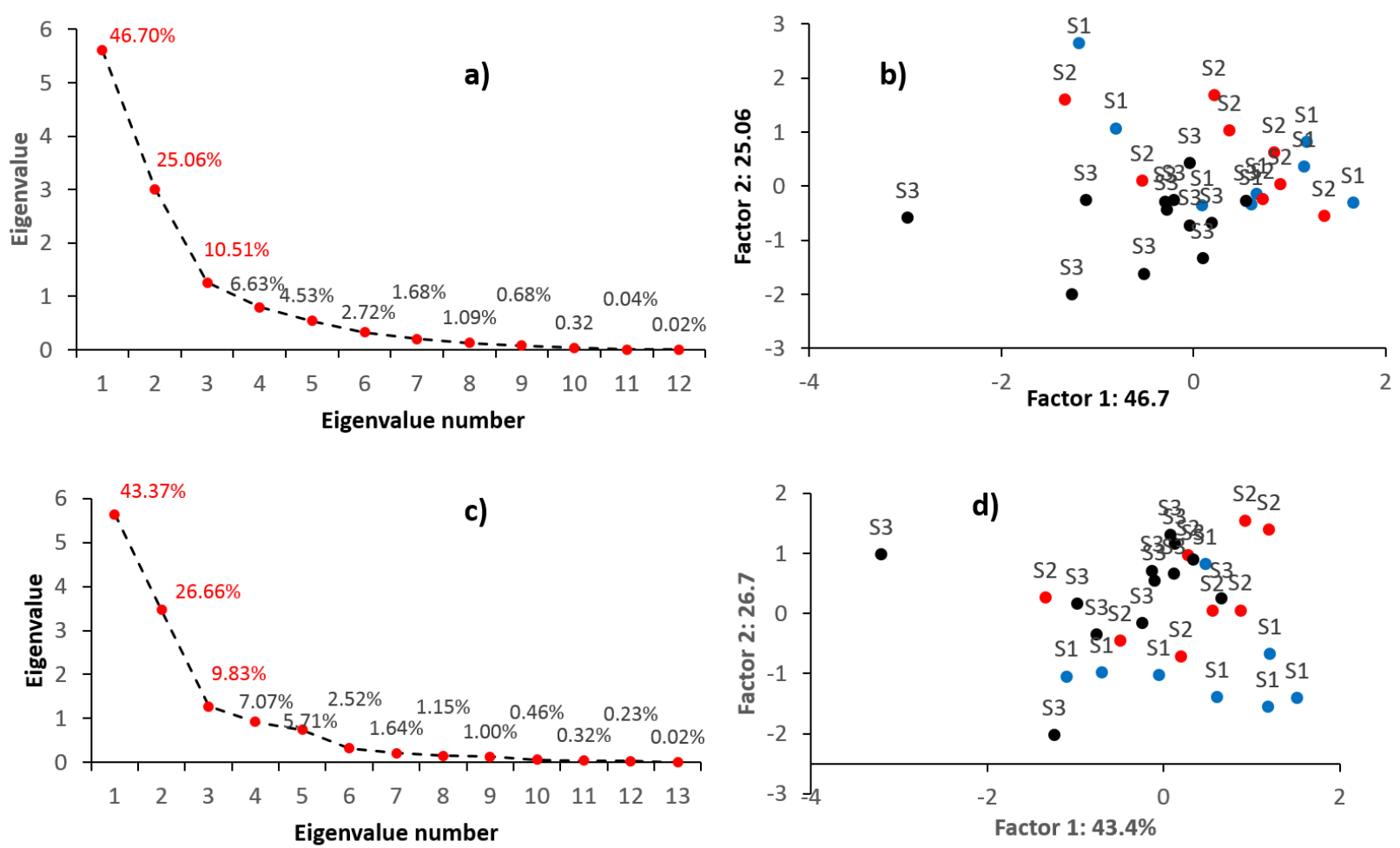
Figure $5:$ a) Scree plot output from the PCA for the spatial sediment source discrimination based on

287 geochemical tracers selected by $T R T+K W$, b) projection of the cases on the principal component plane using PCA based on geochemical tracers selected by TRT+KW, c) Scree plot output from the PCA for the spatial sediment source discrimination based on geochemical tracers selected by RTM+KW, and; d) projection of the cases on the principal component plane using PCA based on geochemical tracers selected by RTM+KW. S1, S2 and S3 indicate samples collected from the spatial sources represented by the western, central and eastern sub-basins, respectively.

\subsection{Bi-plots as a further test for identify conservative tracers}

Bi-plots of the 14 geochemical tracers (Al, Ce, Hf, Li, Nb, Rb, Sc, Ca, Cu, Eu, La, Zr, Mn and

P) comprising the final composite signatures selected using TRT+KW+DFA, RTM+KW+DFA,

297 TRT+KW+PCA and RTM+KW+PCA were constructed as a further test for geochemical tracer

298 conservation (Fig.6). These bi-plots confirmed the conservative behaviour of the final

299 geochemical tracers during sediment mobilization and delivery to the sampling points at the

300 outlet of the study catchment since the sub-basin spatial source and target sediment samples

301 plotted in the same space on each plot. Plots wherein the samples do not fall in the same space

302 indicate non-conservative behaviour of the geochemical tracers in question. Several studies have 303 reported the inclusion of bi-plots for identifying conservative tracers in SSF (e.g., Pulley and 304 Collins, 2018; Owens et al., 2012; Smith and Blake, 2014; Martínez-Carreras et al., 2010). 

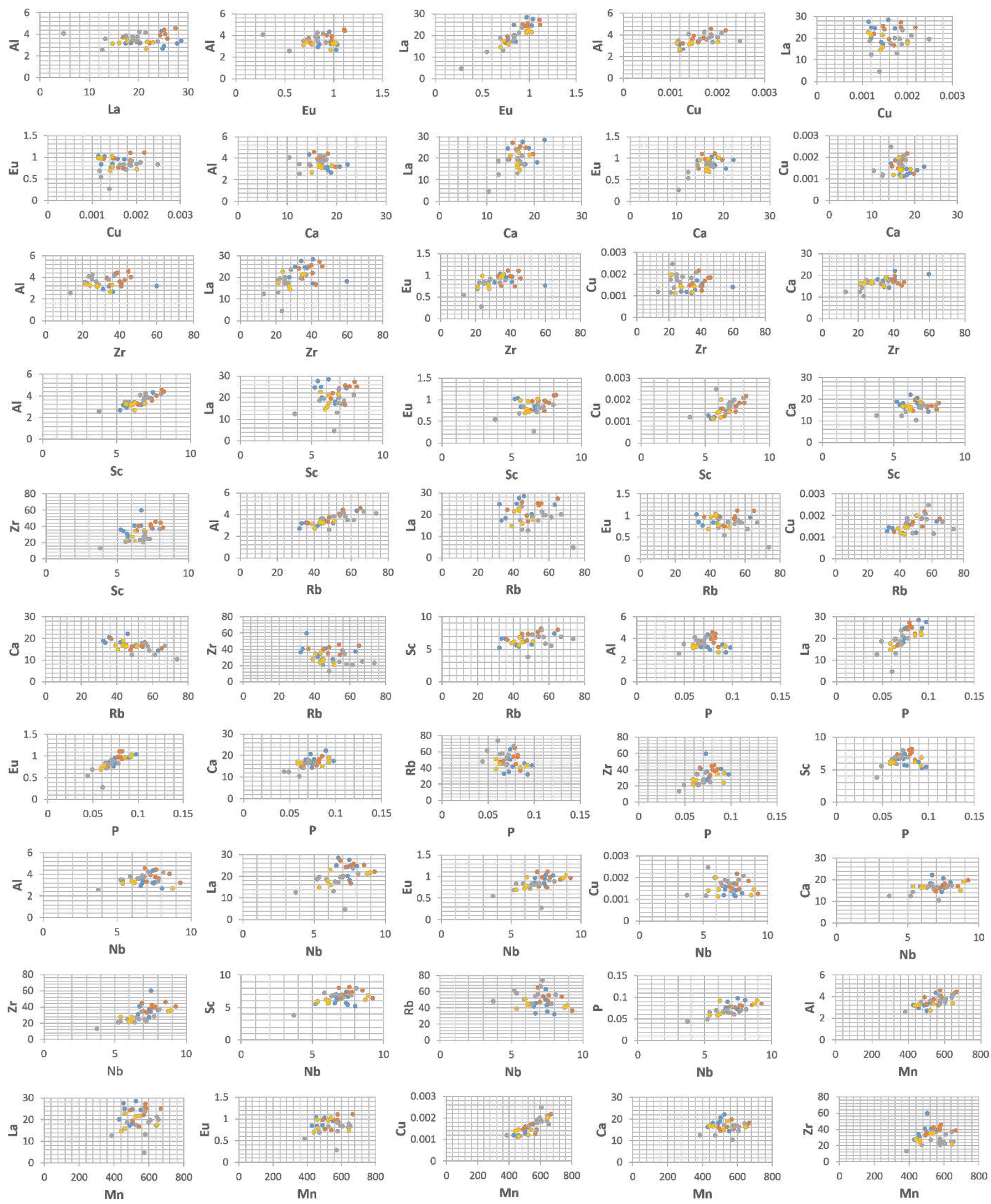

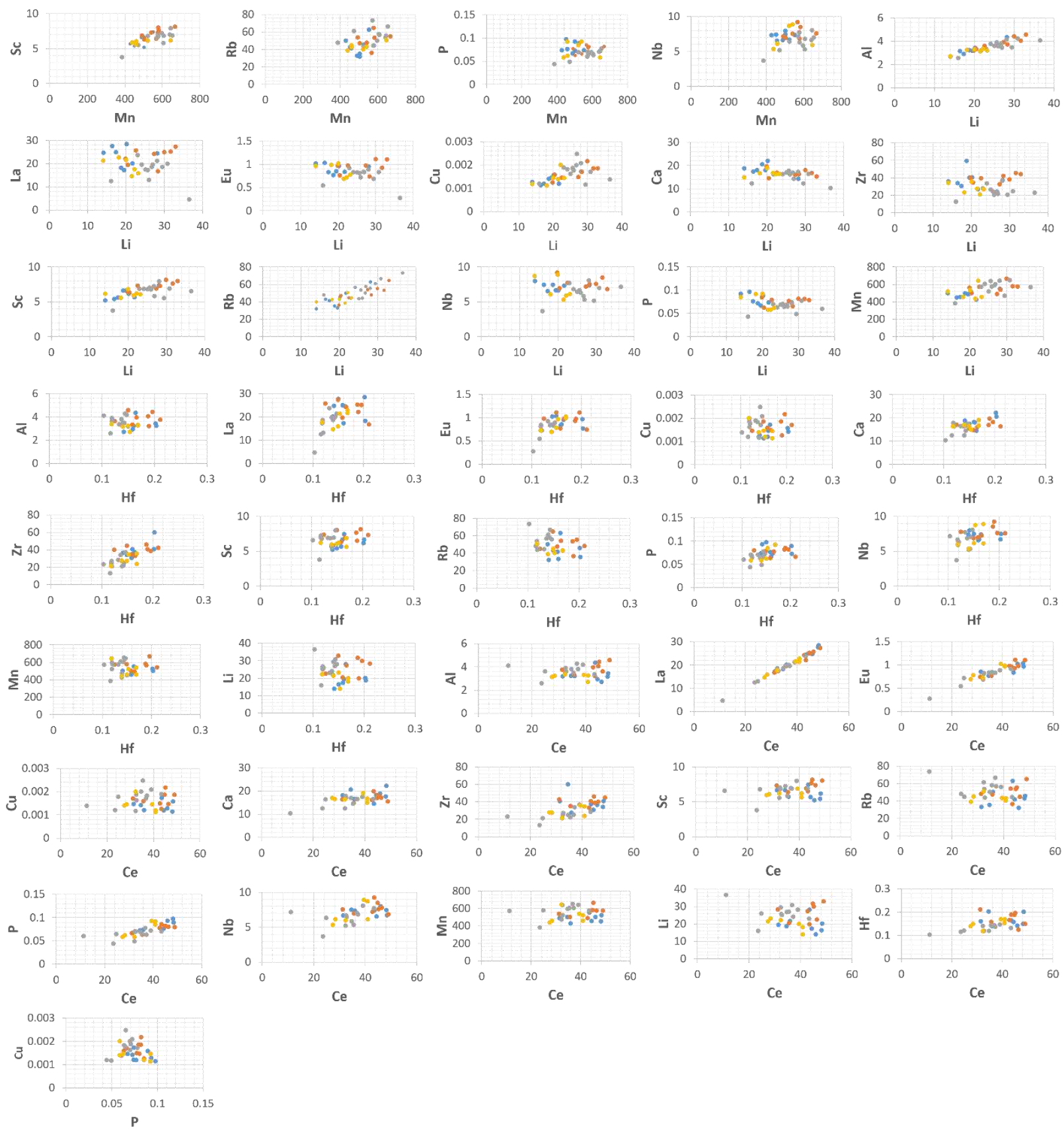

311 Figure 6: The bi-plots of the geochemical tracers comprising the final composite signatures selected using 312 TRT+KW+DFA, RTM+KW+DFA, TRT+DFA+PCA and RTM+DFA+PCA for discriminating the three sub-basin 313 spatial sediment sources. The blue, orange, grey and gold points indicate the samples collected from the 314 western, central and eastern sub-basins and the target sediment samples, respectively. 

estimated by GLUE

The uncertainty ranges (with $95 \%$ confidence limits) of the estimated source contributions and the their cumulative distributions for the six target sediment samples collected

320 from the outlet of the Mehran River estimated by GLUE using the signatures selected by the 321 different combinations of the statistical tests are presented in Figure 7. Using the final composite 322 signature selected by TRT+KW+DFA and RTM+KW+DFA (Fig. 7a), the contributions from the 323 western sub-basin to target sediment sample S1 were predicted to dominate and ranged 324 between $42 \%$ and $72 \%$, compared with 1 to $27 \%$ from the central sub-basin, and 19 to $35 \%$ from 325 the eastern sub-basin. For target sediment sample S2, the corresponding respective 326 contributions, using the same final composite signature, ranged between $1-51 \%, 0.2-21 \%$ and 48 -

$32790 \%$. The western sub-basin contributed $1-40 \%$ for S3, whereas the central and eastern sub328 basins contributed 0.5 to $30 \%$, and 57 to $90 \%$, respectively. The ranges of the contributions from 329 the western, central and eastern sub-basins spatial sources to S4 ranged between 0.9 to $41 \%, 5$ 330 to $30 \%$, and 57 to $91 \%$, respectively. The predicted contributions from the western sub-basin to 331 S5, ranged between 0.6-33\%, whereas the corresponding contributions from the central and 332 eastern sub-basins ranged between $0.7-37 \%$ and $59-90 \%$, respectively. The predicted 333 contributions from the western sub-basin to S6 ranged between 26 to 51\%, whereas the 334 contributions from the central and eastern sub-basins ranged between 26 to $49 \%$, and 19 to $28 \%$, 335 respectively. The results for the predicted spatial source contributions using GLUE and the final 337 composite signature selected by TRT+KW+PCA (Fig. 7b) suggested that the ranges of the 
contributions from the western, central and eastern sub-basins spatial sources to S1 were 38 to $76 \%, 1$ to $30 \%$, and 20 to $37 \%$, respectively. The western sub-basin contributed $1-52 \%$ of $S 2$, whereas the central and eastern sub-basins contributed 0.2 to $20 \%$, and 46 to $91 \%$, respectively. The corresponding respective contributions to S3 ranged between 1-41\%, 0.5-39\% and 57\%-91\%. For target sediment sample S4, the contribution from the western sub-basin ranged between $0.8-41 \%$, whereas the corresponding contributions from the central and eastern sub-basins ranged between $0.5-30 \%$ and $57-91 \%$, respectively. The ranges of the contributions from the western, central and eastern sub-basins spatial sources to S5 were 0.8 to $40 \%, 5$ to $30 \%$, and 57 to $91 \%$, respectively. The predicted contributions from the western, central and eastern subbasins to 66 , ranged between $40-81 \%, 1-35 \%$ and $14-31 \%$, respectively.

Finally, the results for the predicted spatial source apportionment using GLUE and the final composite signature selected by RTM+KW+PCA (Fig. 7c), indicated that the contribution of the western sub-basin to target sediment sample S1, ranged between $53-91 \%$, whereas the corresponding contributions from the central and eastern sub-basins range between $0.6-22 \%$ and $1-37 \%$, respectively. The contributions from the western sub-basin to target sediment sample S2 were predicted to dominate and ranged between $51 \%$ and $90 \%$, compared with 0.3 to $23 \%$ from the central sub-basin, and 15 to $47 \%$ from the eastern sub-basin. The eastern sub-basin was predicted to be the dominant source of target sediment samples S3 (42-91\%), S4 (48-90\%) and S5 (57-91\%), whereas the corresponding predicted contributions from the western and central spatial sub-basins ranged between $2-56 \%, 2-49 \%$ and $1-40 \%$, and $0.3-17 \%, 3-19 \%$ and $0.4-30 \%$, respectively. The ranges of the contributions from the western, central and eastern sub-basins spatial sources to 56 were 53 to $90 \%, 7$ to $25 \%$, and 2 to $32 \%$, respectively. 

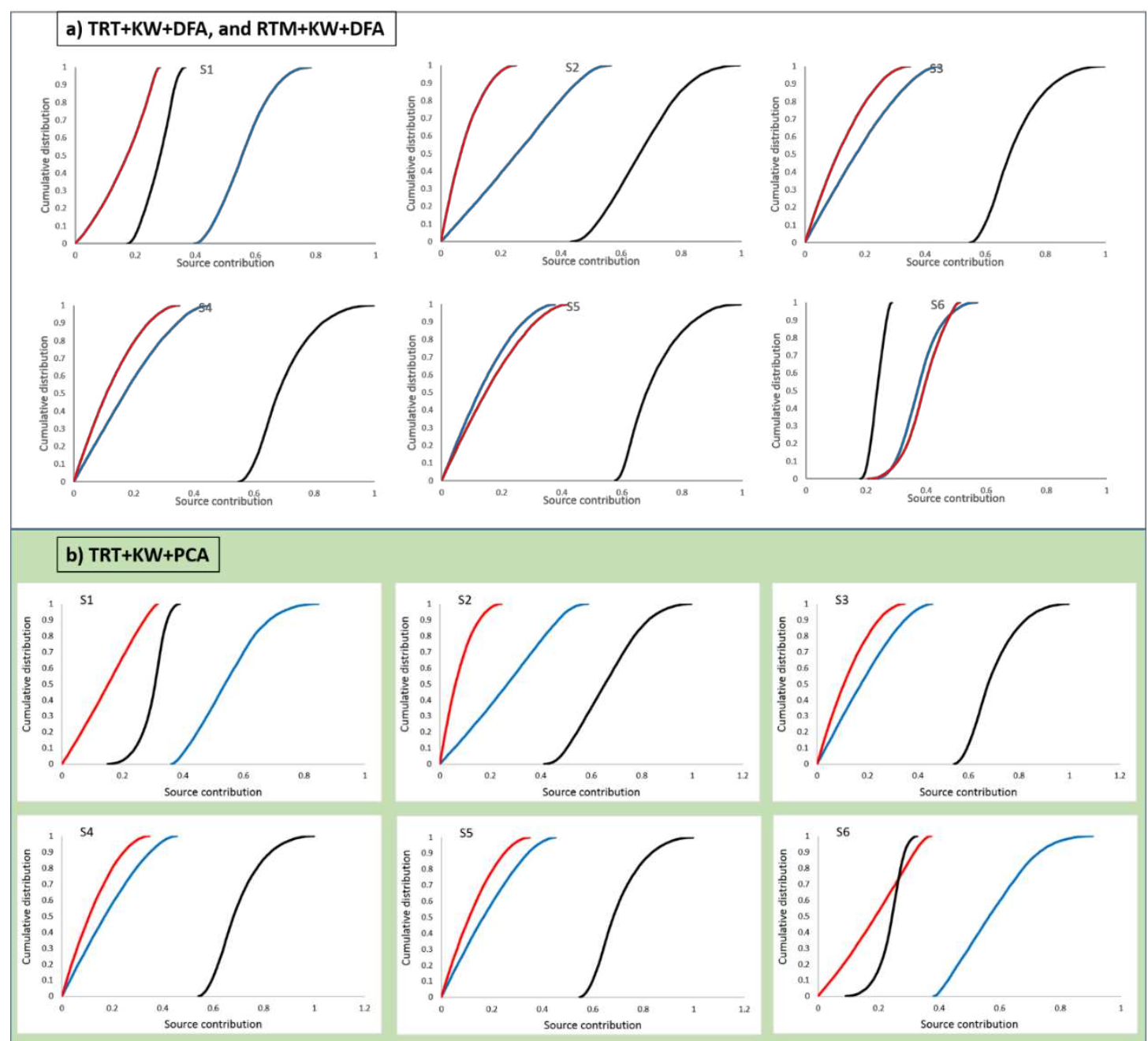

\section{c) $R T M+K W+P C A$}
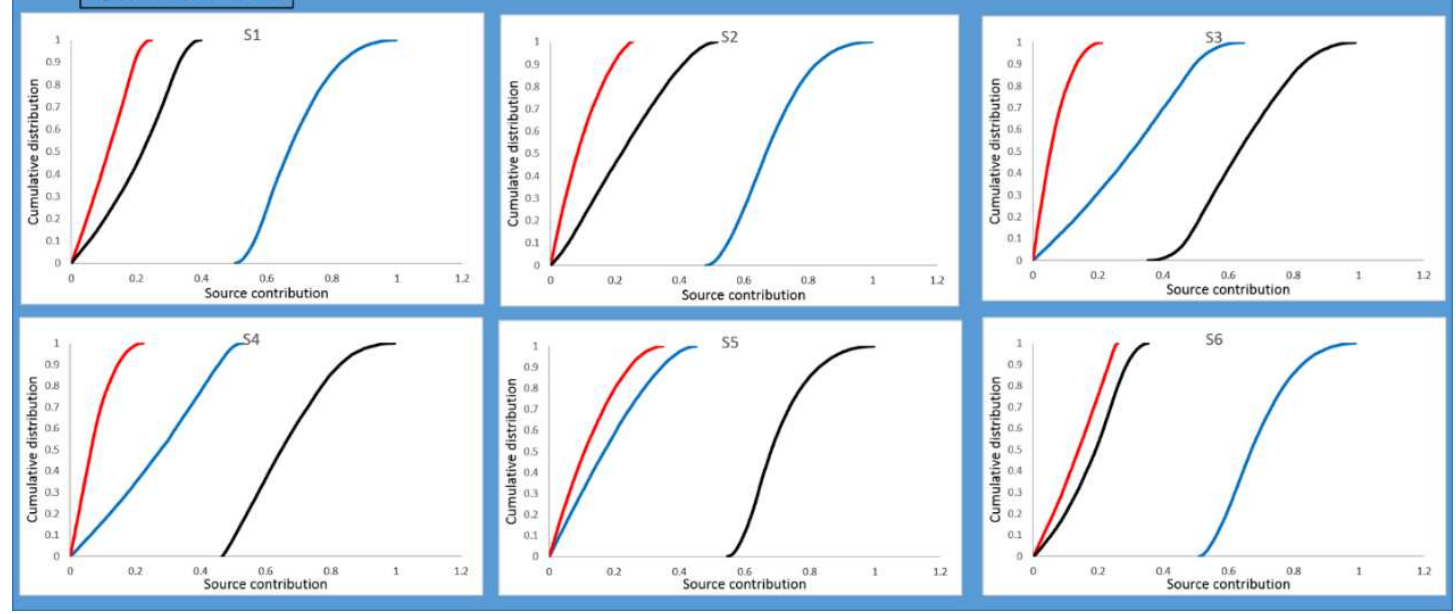

Figure 7: The cumulative distributions for the predicted contributions from the three sub-basin spatial sources (western sub-basin - blue line; central sub-basin - red line, and; eastern sub-basin - black line) modelled using GLUE based on the final composite signatures selected using the four different combinations of statistical tests. 
The contributions from the three sub-basins estimated by GLUE (with 95\% confidence

367 limits) using the four different statistical combinations (TRT+KW+DFA, RTM+KW+DFA, $368 \mathrm{TRT}+\mathrm{KW}+\mathrm{PCA}$ and $\mathrm{RTM}+\mathrm{KW}+\mathrm{PCA}$ ) including their overall means and the corresponding estimates 369 of MAF and GOF are presented in Figure 8 and Table 5. The results of apportionment by GLUE 370 using TRT+KW+DFA and RTM+KW+DFA shows that the overall mean contributions from the 371 western, central and eastern sub-basins ranged between $10-60 \%, 0.3$ to $16 \%$ and $38 \%$ to $77 \%$, 372 respectively (Fig. 8a), and the overall respective mean contributions were estimated at $36 \%, 6 \%$ 373 and $58 \%$ (Table 5 ). Based on the $\operatorname{MAF}(\geq 80 \%$, exception MAF $=78.3 \%$ for target sediment sample 374 S2) and GOF ( $\geq 95 \%$ ) results, the GLUE procedure was able to predict the measured 375 concentrations in the target sediment samples of the tracers comprising these two final 376 composite signatures. Based on the final composite signature selected using TRT+KW+PCA, the 377 range of the overall mean contributions of the western sub-basin was predicted to be $1-42 \%$ 378 (with an overall mean of $20 \%$ ), whereas the corresponding contributions of the central and 379 western sub-basin spatial sources ranged between $0.5-30 \%$ (overall mean $14 \%$ ) and $55-84 \%$ 380 (overall mean 68\%), respectively (Fig. 8b). Based on MAF (> 84\%) and GOF ( $\geq 97 \%$ ), the predicted 381 tracer values using GLUE in combination with the final composite signature selected by 382 TRT+KW+PCA were more accurate than the predictions provided by GLUE with TRT+KW+DFA, $383 \mathrm{RTM}+\mathrm{KW}+\mathrm{DFA}$ and RTM+KW+PCA. The overall mean contributions, provided by GLUE in 384 combination with the final composite signature selected using RTM+KW+PCA, from the western, 385 central and eastern sub-basin spatial sources ranged between 17-69\% (overall mean 41\%), 0.2$38612 \%$ (overall mean 5\%) and $29-76 \%$ (overall mean 54\%), respectively (Fig. 8c). Among the four 
387 different statistical combinations, predictions provided by GLUE with RTM+KW+PCA, with a MAF $388=89.3 \%$ and a GOF $=98.6 \%$, had the lowest accuracy with respect to predicting the measured 389 tracer concentrations in the target sediment samples.

390

391 

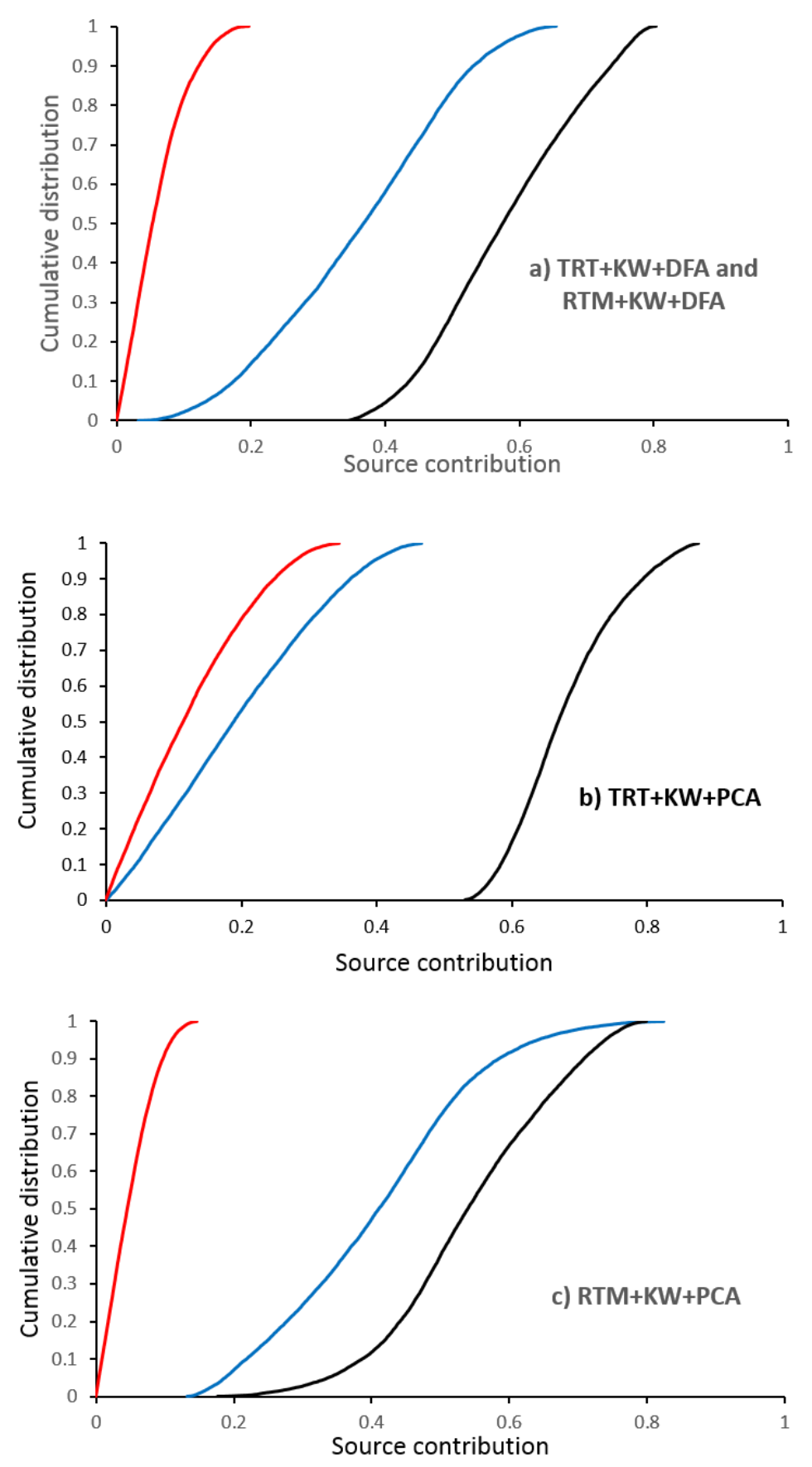

393 Figure 8: The cumulative distributions for the overall mean contributions of the three sub-basin spatial 394 sediment sources (western sub-basin - blue line, central sub-basin - red line and eastern sub-basin - black 395 line) modelled using GLUE with the different combinations of the statistical tests. 
Table 5: The contributions of the three sub-basin spatial sources estimated by GLUE and the final composite signatures selected using different statistical tests and the corresponding values of MAF and GOF for predicting the measured geochemical tracer concentrations in the six target sediment samples

400 (S1-S6).

\begin{tabular}{|c|c|c|c|c|c|c|}
\hline $\begin{array}{l}\text { Statistical tests } \\
\text { combinations }\end{array}$ & $\begin{array}{l}\text { Target } \\
\text { sediment } \\
\text { sample }\end{array}$ & $\begin{array}{l}\text { Western sub- } \\
\text { basin }\end{array}$ & $\begin{array}{l}\text { Central sub- } \\
\text { basin }\end{array}$ & $\begin{array}{l}\text { Eastern sub- } \\
\text { basin }\end{array}$ & $\begin{array}{l}\text { MAF } \\
(\%)\end{array}$ & $\begin{array}{l}\text { GOF } \\
(\%)\end{array}$ \\
\hline TRT+KW+DFA and & S1 & 56 & 16 & 28 & 95.3 & 99.6 \\
\hline \multirow[t]{6}{*}{ RTM+KW+DFA } & S2 & 25 & 8 & 68 & 78.3 & 95.2 \\
\hline & S3 & 18 & 12 & 70 & 88.4 & 97.9 \\
\hline & S4 & 18 & 12 & 70 & 92.1 & 99.1 \\
\hline & S5 & 14 & 16 & 70 & 80.5 & 95.6 \\
\hline & S6 & 37 & 39 & 24 & 93.4 & 98.8 \\
\hline & $\begin{array}{l}\text { Overall } \\
\text { mean }\end{array}$ & 36 & 6 & 58 & 93.8 & 99.6 \\
\hline \multirow[t]{7}{*}{$\mathrm{TRT}+\mathrm{KW}+\mathrm{PCA}$} & S1 & 55 & 15 & 30 & 90.4 & 97.3 \\
\hline & S2 & 27 & 7 & 66 & 84.2 & 97.1 \\
\hline & S3 & 18 & 12 & 70 & 88 & 97.6 \\
\hline & S4 & 18 & 12 & 70 & 91.8 & 99.1 \\
\hline & S5 & 18 & 12 & 70 & 87.8 & 96.9 \\
\hline & S6 & 57 & 19 & 24 & 97.7 & 99.9 \\
\hline & $\begin{array}{l}\text { Overall } \\
\text { mean }\end{array}$ & 20 & 12 & 68 & 95.4 & 99.6 \\
\hline \multirow[t]{7}{*}{ RTM+KW+PCA } & S1 & 68 & 11 & 21 & 78.5 & 90.6 \\
\hline & S2 & 68 & 9 & 23 & 76.2 & 92.3 \\
\hline & S3 & 30 & 6 & 64 & 83.7 & 96.5 \\
\hline & S4 & 27 & 7 & 66 & 88.9 & 98.4 \\
\hline & S5 & 18 & 12 & 70 & 84.4 & 96.5 \\
\hline & S6 & 68 & 14 & 18 & 96.3 & 99.8 \\
\hline & $\begin{array}{l}\text { Overall } \\
\text { mean }\end{array}$ & 41 & 5 & 54 & 89.3 & 98.6 \\
\hline
\end{tabular}

401

3.6 Testing the predicted source proportions with virtual sediment (VS) mixtures

The ten VS samples with different known mixtures presented in Table 6 were used to

404 evaluate the accuracy of the GLUE models using final composite signatures selected by different

405 combinations of the statistical tests for discriminating the three sub-basin spatial sources. The

406 values of the MAE for the GLUE with TRT+KW+DFA and RTM+KW+DFA ranged between $30 \%$ for

407 VS7 to $2 \%$ for VS9 and VS10, whereas the corresponding values of the RMSE ranged between $2 \%$ 
408 for VS9 and $36 \%$ for VS7. The highest values for MAE and RMSE, or the lowest accuracy, was 409 estimated for VS7 with known contributions of 60\% (western sub-basin), $20 \%$ (central sub-basin) 410 and $20 \%$ (eastern sub-basin), compared with predicted corresponding contributions of $16 \%$ 411 (western sub-basin), 61\% (central sub-basin) and 23\% (eastern sub-basin). Among the VS 412 mixtures, the highest accuracy was returned for VS9 with known contributions of 20\% (western 413 sub-basin), 20\% (central sub-basin) and 60\% (eastern sub-basin), and predicted contributions of $41420 \%$ (western sub-basin), 17\% (central sub-basin) and 63\% (eastern sub-basin). The values of the 415 MAE and RMSE were estimated to be less than $20 \%$ for eight VS mixtures (VS2, VS3, VS4, VS5, 416 VS6, VS8, VS9 and VS10) but $\geq 28 \%$ for VS1 and VS7.

418 GLUE provided accurate predictions of the spatial source contributions in the study area. Equally 419 successful applications of GLUE for source fingerprinting aeolian sands and atmospheric dust, in 420 Australia and Iran respectively, have been reported by Telfer et al., (2020) and Behrooz et al., 421 (2019). The GLUE framework can therefore return acceptable accurate estimates of source 422 contributions in different environmental settings and for different types of target sediment. 
428 Table 6: Comparison of the modelled and known contributions from the three spatial sub-basin sources 429 to the target sediment samples (VS1-VS10) using GLUE and virtual sediment (VS) mixtures.

\begin{tabular}{|c|c|c|c|c|c|c|c|c|c|}
\hline \multirow{2}{*}{$\begin{array}{l}\text { Statistical } \\
\text { tests } \\
\text { combinations }\end{array}$} & \multirow{2}{*}{$\begin{array}{l}\text { VS } \\
\text { sample } \\
\text { no }\end{array}$} & \multicolumn{3}{|c|}{$\begin{array}{l}\text { VS mixture known source } \\
\text { proportions }\end{array}$} & \multicolumn{3}{|c|}{$\begin{array}{l}\text { GLUE predicted source } \\
\text { proportions }\end{array}$} & \multirow[t]{2}{*}{ MAE } & \multirow[t]{2}{*}{ RMSE } \\
\hline & & $\begin{array}{l}\text { Western } \\
\text { sub- } \\
\text { basin }\end{array}$ & $\begin{array}{l}\text { Central } \\
\text { sub- } \\
\text { basin }\end{array}$ & $\begin{array}{l}\text { Eastern } \\
\text { sub- } \\
\text { basin }\end{array}$ & $\begin{array}{l}\text { Western } \\
\text { sub- } \\
\text { basin }\end{array}$ & $\begin{array}{l}\text { Central } \\
\text { sub- } \\
\text { basin }\end{array}$ & $\begin{array}{l}\text { Eastern } \\
\text { sub- } \\
\text { basin }\end{array}$ & & \\
\hline \multirow{10}{*}{$\begin{array}{l}\text { TRT+KW+DFA } \\
\text { and } \\
\text { RTM+KW+DFA }\end{array}$} & VS1 & 80 & 10 & 10 & 43 & 52 & 5 & 28 & 33 \\
\hline & VS2 & 10 & 80 & 10 & 33 & 60 & 7 & 16 & 18 \\
\hline & VS3 & 10 & 10 & 80 & 13 & 17 & 70 & 6 & 8 \\
\hline & VS4 & 40 & 30 & 30 & 51 & 27 & 22 & 7 & 8 \\
\hline & VS5 & 30 & 40 & 30 & 32 & 43 & 25 & 4 & 4 \\
\hline & VS6 & 30 & 30 & 40 & 20 & 48 & 32 & 12 & 13 \\
\hline & VS7 & 60 & 20 & 20 & 16 & 61 & 23 & 30 & 36 \\
\hline & VS8 & 20 & 60 & 20 & 26 & 51 & 23 & 6 & 7 \\
\hline & VS9 & 20 & 20 & 60 & 20 & 17 & 63 & 2 & 2 \\
\hline & VS10 & 33.3 & 33.3 & 33.3 & 32 & 31 & 37 & 2 & 3 \\
\hline \multirow[t]{10}{*}{$\mathrm{TRT}+\mathrm{KW}+\mathrm{PCA}$} & VS1 & 80 & 10 & 10 & 30 & 66 & 4 & 38 & 44 \\
\hline & VS2 & 10 & 80 & 10 & 39 & 47 & 14 & 22 & 26 \\
\hline & VS3 & 10 & 10 & 80 & 14 & 11 & 75 & 4 & 5 \\
\hline & VS4 & 40 & 30 & 30 & 20 & 71 & 9 & 28 & 29 \\
\hline & VS5 & 30 & 40 & 30 & 29 & 21 & 50 & 14 & 17 \\
\hline & VS6 & 30 & 30 & 40 & 7 & 44 & 49 & 15 & 17 \\
\hline & VS7 & 60 & 20 & 20 & 62 & 11 & 27 & 6 & 7 \\
\hline & VS8 & 20 & 60 & 20 & 25 & 69 & 6 & 9 & 10 \\
\hline & VS9 & 20 & 20 & 60 & 5 & 40 & 55 & 13 & 15 \\
\hline & VS10 & 33.3 & 33.3 & 33.3 & 26 & 11 & 63 & 20 & 22 \\
\hline \multirow[t]{10}{*}{$\mathrm{RTM}+\mathrm{KW}+\mathrm{PCA}$} & VS1 & 80 & 10 & 10 & 46 & 50 & 4 & 26 & 30 \\
\hline & VS2 & 10 & 80 & 10 & 17 & 70 & 13 & 7 & 8 \\
\hline & VS3 & 10 & 10 & 80 & 13 & 17 & 70 & 7 & 8 \\
\hline & VS4 & 40 & 30 & 30 & 42 & 35 & 23 & 5 & 5 \\
\hline & VS5 & 30 & 40 & 30 & 68 & 16 & 16 & 25 & 27 \\
\hline & VS6 & 30 & 30 & 40 & 9 & 59 & 32 & 19 & 21 \\
\hline & VS7 & 60 & 20 & 20 & 14 & 68 & 18 & 32 & 38 \\
\hline & VS8 & 20 & 60 & 20 & 17 & 50 & 33 & 9 & 9 \\
\hline & VS9 & 20 & 20 & 60 & 15 & 21 & 64 & 3 & 4 \\
\hline & VS10 & 33.3 & 33.3 & 33.3 & 17 & 46 & 37 & 11 & 12 \\
\hline
\end{tabular}

430

431

\section{Study limitations}

Any SSF study necessarily has inherent limitations and uncertainties. Available resources

433 and in many cases, the nature of the landscape in question, inevitably serve to constrain field 434 access and effort and sampling campaigns. In this study, a conventional confluence-based 
435 approach to estimating sub-basin spatial sediment source contributions (e.g., Collins et al., 1996;

436 Vale et al., 2016) was implemented using limited sampling of the spatial sources and downstream

437 target sediment and the single campaign nature of these samples should be borne in mind when

438 interpreting the results. The river bed sediment samples used to represent the spatial sources

439 and the downstream target sediment were not age-dated (e.g., Matisoff et al., 2005; Gellis et al.,

$4402016,2019)$ and so it is not possible to confirm the time period represented by the source

441 apportionment estimates. Although a combination of two range tests and tracer biplots was used

442 to help evidence tracer conservatism, it remains widely reported that these approaches fail to

443 attest to the complete absence of transformation during sediment mobilization and routing. With

444 regards the constituent tracers selected in the final composite signatures used in our work, Ca,

$445 \mathrm{Mn}$ and $\mathrm{P}$ have been reported as being susceptible to phase changes, whereas in comparison, Al,

$446 \mathrm{Ce}, \mathrm{Eu}, \mathrm{La}$ and Sc have been reported as being far less susceptible to mobility between phases

447 (Meybeck and Helmer, 1989). The composite signatures selected in this study are essentially

448 statistical solutions generated by different combinations of tests and here it is informative to

449 bear in mind that some studies have attempted to focus on knowledge-based pre-selection of

450 tracers (e.g., Laceby et al., 2015b; Batista et al., 2019). Finally, Vs mixtures were used as a

451 convenient and widely adopted (e.g., Palazon et al., 2015; Sherriff et al., 2015) means to assess

452 the accuracy of the predicted spatial source proportions, since independent monitoring data for

453 the sediment loads emitted from the tributary sub-catchments was not available. The lack of

454 independent evidence to validate SSF results is common to almost all existing published studies,

455 although a few exceptions exist (e.g., Collins et al., 1998; Stone et al., 2014).

456 5. Conclusions 
458 the spatial source contributions from three sub-basins of a large arid catchment in southern Iran 459 using SSF within a GLUE framework. Based on MAF and GOF, all four tracer models performed 460 well, but GLUE with the final composite signature selected by the more traditional statistical 461 procedures (TRT+KW+DFA and RTM+KW+DFA) for source discrimination performed slightly 462 better than the two other models (GLUE with TRT+KW+PCA, and GLUE with RTM+KW+PCA). Our 463 results for sediment source apportionment can help managers target spatial priorities for 464 interventions to help decrease sediment loads and mitigate their negative effects in the Mehran 465 study catchment. On the basis of our experience with this study, we recommend applying the 466 SSF approach within a GLUE framework with the traditional statistical tests for quantifying source 467 contributions. To confirm the wider applicability of our case study findings, our analyses herein 468 should be replicated for estimating the sources of aeolian and fluvial sediments and the 469 associated uncertainties and accuracies in catchments and landscapes located in different 470 regions around the world experiencing severe soil erosion and sediment delivery by either water 471 or wind.

\section{Acknowledgements}

473 This paper was written based on the results from Atefeh Fatthahi's PhD dissertation. The authors 474 would like to thank the Faculty of Agriculture and Natural Resources, University of Hormozgan, 475 Iran, for supporting this joint research project.

\section{References}


Batista, P. V., Laceby, J. P., Silva, M. L., Tassinari, D., Bispo, D. F., Curi, N., ... \& Quinton, J.

N. (2019). Using pedological knowledge to improve sediment source apportionment in tropical environments. Journal of Soils and Sediments, 19(9), 3274-3289.

Behrooz, R. D., Gholami, H., Telfer, M. W., Jansen, J. D., \& Fathabadi, A. (2019). Using GLUE to pull apart the provenance of atmospheric dust. Aeolian Research, 37, 1-13.

Beven, K., \& Binley, A. (1992). The future of distributed models: model calibration and uncertainty prediction. Hydrological processes, 6(3), 279-298.

Brewer, M. J., Filipe, J. A., Elston, D. A., Dawson, L. A., Mayes, R. W., Soulsby, C., \& Dunn, S. M. (2005). A hierarchical model for compositional data analysis. Journal of agricultural, biological, and environmental statistics, 10(1), 19-34.

Collins, A. L., Blackwell, M., Boeckx, P., Chivers, C. A., Emelko, M., Evrard, O., ... \& Harris, P. (2020). Sediment source fingerprinting: benchmarking recent outputs, remaining challenges and emerging themes. Journal of Soils and Sediments, 20(12), 4160-4193.

Collins, A. L., Pulley, S., Foster, I. D., Gellis, A., Porto, P., \& Horowitz, A. J. (2017). Sediment source fingerprinting as an aid to catchment management: a review of the current state of knowledge and a methodological decision-tree for end-users. Journal of Environmental Management, 194, 86-108.

Collins, A. L., Walling, D. E., \& Leeks, G. J. L. (1998). Use of composite fingerprints to determine the provenance of the contemporary suspended sediment load transported by rivers. Earth Surface Processes and Landforms: The Journal of the British Geomorphological Group, 23(1), 31-52.

Collins, A. L., \& Walling, D. E. (2002). Selecting fingerprint properties for discriminating potential suspended sediment sources in river basins. Journal of hydrology, 261(1-4), 218-244.

Collins, A., Walling, D., \& Leeks, G. J. L. (1996). Composite fingerprinting of the spatial source of fluvial suspended sediment: a case study of the Exe and Severn River basins, United Kingdom. Géomorphologie: relief, processus, environnement, 2(2), 41-53.

Collins, A. L., Walling, D. E., \& Leeks, G. J. (1997). Fingerprinting the origin of fluvial suspended sediment in larger river basins: combining assessment of spatial provenance and source type. Geografiska Annaler: Series A, Physical Geography, 79(4), 239-254. 
Collins, A. L., Walling, D. E., \& Leeks, G. J. L. (1998). Use of composite fingerprints to determine the provenance of the contemporary suspended sediment load transported by rivers. Earth Surface Processes and Landforms: The Journal of the British Geomorphological Group, 23(1), 31-52.

Collins, A. L., Zhang, Y., Walling, D. E., Grenfell, S. E., \& Smith, P. (2010). Tracing sediment loss from eroding farm tracks using a geochemical fingerprinting procedure combining local and genetic algorithm optimisation. Science of the total environment, 408(22), 5461-5471.

Collins, A. L., Zhang, Y., Walling, D. E., Grenfell, S. E., Smith, P., Grischeff, J., ... \& Brogden, D. (2012). Quantifying fine-grained sediment sources in the River Axe catchment, southwest England: Application of a Monte Carlo numerical modelling framework incorporating local and genetic algorithm optimisation. Hydrological Processes, 26(13), 1962-1983.

Cooper, R. J., Krueger, T., Hiscock, K. M., \& Rawlins, B. G. (2014). Sensitivity of fluvial sediment source apportionment to mixing model assumptions: $A B$ ayesian model comparison. Water Resources Research, 50(11), 9031-9047.

Dutton, C., Anisfeld, S. C., \& Ernstberger, H. (2013). A novel sediment fingerprinting method using filtration: Application to the Mara River, East Africa. Journal of Soils and Sediments, 13(10), 1708-1723.

Egozcue, J. J., Pawlowsky-Glahn, V., Mateu-Figueras, G., \& Barcelo-Vidal, C. (2003). Isometric logratio transformations for compositional data analysis. Mathematical Geology, 35(3), 279-300.

Gellis, A. C., \& Walling, D. E. (2011). Sediment source fingerprinting (tracing) and sediment budgets as tools in targeting river and watershed restoration programs. Stream restoration in dynamic fluvial systems: scientific approaches, analyses, and tools, 194, 263-291.

Gellis, A. C., Fitzpatrick, F. A., \& Schubauer-Berigan, J. (2016). A manual to identify sources of fluvial sediment (No. EPA/600/R-16/210). US Environmental Protection Agency. Gellis, A. C., Fuller, C. C., Van Metre, P., Filstrup, C. T., Tomer, M. D., Cole, K. J., \& Sabitov, T. Y. (2019). Combining sediment fingerprinting with age-dating sediment using fallout radionuclides for an agricultural stream, Walnut Creek, lowa, USA. Journal of Soils and Sediments, 19(9), 3374-3396. 
Gholami, H., Rahimi, S., Fathabadi, A., Habibi, S., \& Collins, A. L. (2020). Mapping the spatial sources of atmospheric dust using GLUE and Monte Carlo simulation. Science of The Total Environment, 138090.

Gholami, H., Telfer, M. W., Blake, W. H., \& Fathabadi, A. (2017). Aeolian sediment fingerprinting using a Bayesian mixing model. Earth Surface Processes and Landforms, 42(14), 2365-2376.

Gong, Y., Shen, Z., Hong, Q., Liu, R., \& Liao, Q. (2011). Parameter uncertainty analysis in watershed total phosphorus modeling using the GLUE methodology. Agriculture, ecosystems \& environment, 142(3-4), 246-255. reservoir sediment via two modelling approaches. Science of the Total Environment, 663, 78-96. Horowitz, A. J. (1991). A primer on sediment-trace element chemistry (Vol. 2). Chelsea: Lewis Publishers.

Koiter, A. J., Lobb, D. A., Owens, P. N., Petticrew, E. L., Tiessen, K. H., \& Li, S. (2013). Investigating the role of connectivity and scale in assessing the sources of sediment in an agricultural watershed in the Canadian prairies using sediment source fingerprinting. Journal of Soils and Sediments, 13(10), 1676-1691.

Laceby, J. P., \& Olley, J. (2015). An examination of geochemical modelling approaches to tracing sediment sources incorporating distribution mixing and elemental correlations. 554 Hydrological processes, 29(6), 1669-1685. statistical approaches to element selection for sediment fingerprinting. Journal of Soils and Sediments, 15(10), 2117-2131.

561 Le Gall, M., Evrard, O., Foucher, A., Laceby, J. P., Salvador-Blanes, S., Thil, F., ... \&

562 Ayrault, S. (2016). Quantifying sediment sources in a lowland agricultural catchment pond using 
137Cs activities and radiogenic 87Sr/86Sr ratios. Science of the Total Environment, 566, 968980.

Li, Y., Gholami, H., Song, Y., Fathabadi, A., Malakooti, H., \& Collins, A. L. (2020). Source fingerprinting loess deposits in Central Asia using elemental geochemistry with Bayesian and GLUE models. Catena, 194, 104808.

Liu, B., Niu, Q., Qu, J., \& Zu, R. (2016). Quantifying the provenance of aeolian sediments using multiple composite fingerprints. Aeolian research, 22, 117-122.

Mararakanye, N., \& Sumner, P. D. (2017). Gully erosion: A comparison of contributing factors in two catchments in South Africa. Geomorphology, 288, 99-110.

Martínez-Carreras, N., Krein, A., Gallart, F., Iffly, J. F., Pfister, L., Hoffmann, L., \& Owens, P. N. (2010). Assessment of different colour parameters for discriminating potential suspended sediment sources and provenance: a multi-scale study in Luxembourg. Geomorphology, 118(12), 118-129.

Marzolff, I., Ries, J. B., \& Poesen, J. (2011). Short-term versus medium-term monitoring for detecting gully-erosion variability in a Mediterranean environment. Earth Surface Processes and Landforms, 36(12), 1604-1623.

Massoudieh, A., Gellis, A., Banks, W. S., \& Wieczorek, M. E. (2013). Suspended sediment source apportionment in Chesapeake Bay watershed using Bayesian chemical mass balance receptor modeling. Hydrological Processes, 27(24), 3363-3374.

Matisoff, G., Wilson, C. G., \& Whiting, P. J. (2005). The 7Be/210Pbxs ratio as an indicator of suspended sediment age or fraction new sediment in suspension. Earth Surface Processes and Landforms: The Journal of the British Geomorphological Research Group, 30(9), 1191-1201.

Meybeck, M., \& Helmer, R. (1989). The quality of rivers: from pristine stage to global pollution. Global and Planetary Change, 1(4), 283-309.

Mohammadifar, A., Gholami, H., Comino, J. R., \& Collins, A. L. (2021). Assessment of the interpretability of data mining for the spatial modelling of water erosion using game theory. Catena, 200, 105178. 
Motha, J. A., Wallbrink, P. J., Hairsine, P. B., \& Grayson, R. B. (2003). Determining the sources of suspended sediment in a forested catchment in southeastern Australia. Water resources research, 39(3).

Niu, B., Tan, L., Zhang, X. J., Qu, J., An, Z., Wang, J., ... \& Li, K. (2020). Targeted control of sand hazards for a railway in extremely arid regions using fingerprinting approaches. Geomorphology, 361, 107189.

Nosrati, K., Akbari-Mahdiabad, M., Ayoubi, S., \& Collins, A. L. (2021). An exploratory study on the use of different composite magnetic and colour fingerprints in aeolian sediment provenance fingerprinting. CATENA, 200, 105182.

Nosrati, K., Akbari-Mahdiabad, M., Ayoubi, S., Degos, E., Koubansky, A., Coquatrix, Q., ... \& Collins, A. L. (2020). Storm dust source fingerprinting for different particle size fractions using colour and magnetic susceptibility and a Bayesian un-mixing model. Environmental Science and Pollution Research, 27(25), 31578-31594.

Nosrati, K., \& Collins, A. L. (2019). Fingerprinting the contribution of quarrying to finegrained bed sediment in a mountainous catchment, Iran. River Research and Applications, 35(3), 290-300.

Owens, P. N., Blake, W. H., Giles, T. R., \& Williams, N. D. (2012). Determining the effects of wildfire on sediment sources using $137 \mathrm{Cs}$ and unsupported $210 \mathrm{~Pb}$ : the role of landscape disturbances and driving forces. Journal of Soils and Sediments, 12(6), 982-994.

Palazón, L., Latorre, B., Gaspar, L., Blake, W. H., Smith, H. G., \& Navas, A. (2015). Comparing catchment sediment fingerprinting procedures using an auto-evaluation approach with virtual sample mixtures. Science of the Total Environment, 532, 456-466.

Pulley, S., \& Collins, A. L. (2018). Tracing catchment fine sediment sources using the new SIFT (SedIment Fingerprinting Tool) open source software. Science of the Total Environment, 635, 838-858.

Pulley, S., Collins, A. L., \& Laceby, J. P. (2020). The representation of sediment source group tracer distributions in Monte Carlo uncertainty routines for fingerprinting: An analysis of accuracy and precision using data for four contrasting catchments. Hydrological processes, 34(11), 2381-2400. 
Pulley, S., Foster, I., \& Antunes, P. (2015). The uncertainties associated with sediment

fingerprinting suspended and recently deposited fluvial sediment in the Nene river basin.

Geomorphology, 228, 303-319.

Rowan, J. S., Goodwill, P., \& Franks, S. W. (2000). Uncertainty estimation in fingerprinting suspended sediment sources. In Tracers in geomorphology (pp. 279-290).

Semmens, B. X., Moore, J. W., \& Ward, E. J. (2009). Improving Bayesian isotope mixing models: a response to Jackson et al.(2009). Ecology Letters, 12(3), E6-E8.

Smith, H. G., \& Blake, W. H. (2014). Sediment fingerprinting in agricultural catchments: a critical re-examination of source discrimination and data corrections. Geomorphology, 204, 177-191.

Sherriff, S. C., Franks, S. W., Rowan, J. S., Fenton, O., \& Ó’hUallacháin, D. (2015). Uncertainty-based assessment of tracer selection, tracer non-conservativeness and multiple solutions in sediment fingerprinting using synthetic and field data. Journal of Soils and Sediments, 15(10), 2101-2116.

Stone, M., Collins, A. L., Silins, U., Emelko, M. B., \& Zhang, Y. S. (2014). The use of composite fingerprints to quantify sediment sources in a wildfire impacted landscape, Alberta, Canada. Science of the total environment, 473, 642-650.

Telfer, M. W., Gholami, H., Hesse, P. P., Fisher, A., \& Hartley, R. (2020). Testing models of linear dune formation by provenance analysis with composite sediment fingerprints. Geomorphology, 364, 107208.

Taylor, S. R., \& McLennan, S. M. (1985). The continental crust: its composition and evolution.

Vale, S. S., Fuller, I. C., Procter, J. N., Basher, L. R., \& Smith, I. E. (2016). Characterization and quantification of suspended sediment sources to the Manawatu River, New Zealand. Science of the Total Environment, 543, 171-186.

Walling, D. E. (2005). Tracing suspended sediment sources in catchments and river systems. Science of the total environment, 344(1-3), 159-184.

Walling, D. E. (2013). The evolution of sediment source fingerprinting investigations in fluvial systems. Journal of Soils and Sediments, 13(10), 1658-1675. 
Walling, D. E., Woodward, J. C., \& Nicholas, A. P. (1993). A multi-parameter approach to 649 fingerprinting suspended-sediment sources. IAHS publication, (215), 329-338.

650 Zhang, X. J., \& Liu, B. L. (2016). Using multiple composite fingerprints to quantify fine 651 sediment source contributions: a new direction. Geoderma, 268, 108-118.

652 Zhao, Y., Gao, G. L., Zhang, Y., Ding, G. D., Zhou, J. X., Chen, Y. X., \& Zhou, Q. Z. (2020).

653 Aeolian sediment fingerprinting in the Cuona Lake Section along the Qinghai-Tibetan Railway.

654 Journal of Cleaner Production, 261, 121233.

655 Zhao, Y., Zhou, Q., Gao, G., Ding, G., Zhang, Y., \& Zhou, J. (2021). A new methodological

656 framework coupling computational fluid dynamics and fingerprinting for assessment of aeolian

657 sediment transport processes. CATENA, 204, 105372.

658

659

660

661 